\title{
Low vision impairs implicit sensorimotor adaptation in response to small errors, but not large errors \\ Jonathan S. Tsay ${ }^{1,2}$, Steven Tan ${ }^{3}$, Marlena Chu ${ }^{3}$, Richard B. Ivry ${ }^{1,2}$, Emily A. Cooper $^{2,3}$ \\ ${ }^{1}$ Department of Psychology, University of California, Berkeley \\ ${ }^{2}$ Helen Wills Neuroscience Institute, University of California, Berkeley \\ ${ }^{3}$ Herbert Wertheim School of Optometry and Vision Science, University of California, Berkeley
}

\section{Corresponding author Information:}

$\begin{array}{ll}\text { Name: } & \text { Jonathan S. Tsay } \\ \text { Email: } & \text { xiaotsay2015@berkeley.edu } \\ \text { Address: } & 2121 \text { Berkeley Way West, Berkeley, CA } 94704\end{array}$

Key words: low vision, visuomotor adaptation, optimal integration, sensory uncertainty

\begin{abstract}
Successful goal-directed actions require constant fine-tuning in response to errors introduced by changes in the body and environment. This implicit adaptive process has been assumed to operate in a statistically optimal fashion, reducing its sensitivity to errors when sensory uncertainty is high. However, recent work has shown that visual uncertainty attenuates implicit adaptation for small errors, but not large errors, a result that is at odds with an optimal integration hypothesis. This error size interaction has motivated a new hypothesis that sensory uncertainty impacts the distribution of the perceived error locations but not the system's sensitivity to errors. To examine these competing hypotheses, previous studies have experimentally manipulated uncertainty. But it is unknown which hypothesis best describes motor adaptation to sensory uncertainty experienced during daily life. To address this question, we recruited individuals with low vision due to diverse clinical conditions impacting visual uncertainty and matched controls. The groups were tested on visuomotor tasks designed to isolate implicit adaptation and maintain tight control over the error size. In two experiments, low vision was associated with attenuated implicit adaptation only for small errors, but not for large errors. Taken together with prior work in which visual uncertainty was experimentally manipulated, these results support the notion that increasing sensory uncertainty increases the likelihood that errors are mis-localized but does not affect error sensitivity, offering a novel account for the motor learning deficits seen in low vision.
\end{abstract}




\section{Introduction}

Our ability to enact successful goal-directed actions derives from multiple learning processes (Bond \& Taylor, 2015; Haith, Huberdeau, \& Krakauer, 2015; Keisler \& Shadmehr, 2010; McDougle et al., 2016; McDougle, Bond, \& Taylor, 2015; Taylor \& Ivry, 2011; Taylor, Krakauer, \& Ivry, 2014). Among these processes, implicit motor adaptation ensures that the sensorimotor system remains well-calibrated in response to changes in the body (e.g., muscle fatigue) and in the environment (e.g., a heavy jacket). This adaptive process is driven by sensory prediction errors - the difference between the predicted feedback from a motor command and the actual sensory feedback (Kim, Avraham, \& Ivry, 2020; Shadmehr, Smith, \& Krakauer, 2010).

Previous research suggests that sensory prediction errors drive implicit motor adaptation in a statistically optimal fashion. According to the optimal integration hypothesis, the learning rate for adaptation is based on a weighted signal composed of the feedback and the feedforward prediction (Burge, Ernst, \& Banks, 2008; Körding \& Wolpert, 2004; Wei \& Körding, 2010). Uncertainty, either from temporal delay (Brudner, Kethidi, Graeupner, Ivry, \& Taylor, 2016; Kitazawa, Kohno, \& Uka, 1995) or spatial variability (Burge et al., 2008) reduces the system's sensitivity to the feedback signal and, as such, reduces the rate and extent of implicit adaptation (Burge et al., 2008; Samad, Chung, \& Shams, 2015; Shyr \& Joshi, 2021; van Beers, 2012; van Beers, Wolpert, \& Haggard, 2002; Wei \& Körding, 2010). Importantly if this hypothesis is correct, this attenuating effect of uncertainty should be observed for all error sizes when uncertainty is high (Figure 1a,b).

However, recent studies using novel, more advanced behavioral methods suggest that implicit adaptation is driven by an inflexible system (Kim, Morehead, Parvin, Moazzezi, \& Ivry, 2018; Tsay, Kim, Haith, \& Ivry, 2021), one that saturates when sensory prediction errors are large. Consistent with this notion of inflexibility (and contrary to the optimal integration hypothesis), we recently found that implicit adaptation was only affected by visual uncertainty when the error was small and not when the error was large (Tsay, Avraham, et al., 2020). This error size interaction motivated a new hypothesis centered on how uncertainty impacts the distribution of the perceived error location rather than the system's overall sensitivity to the error. By this mis-localization hypothesis, uncertainty increases the variability of the error distribution: For small errors, this distribution will include trials in which the error is localized to the wrong side of a target (i.e., a "sign flip" of the error to the opposite side of the target relative to the true location of the feedback), resulting in motor corrections in the wrong direction, attenuating the cumulative effect of implicit adaptation. For large errors, sign flips will not be expected even when uncertainty is high. The mis-localization hypothesis predicts that implicit adaptation will not be affected by large errors (Figure 1c). 
bioRxiv preprint doi: https://doi.org/10.1101/2022.01.03.474829; this version posted January 4, 2022. The copyright holder for this preprint (which was not certified by peer review) is the author/funder, who has granted bioRxiv a license to display the preprint in perpetuity. It is made available under aCC-BY-NC-ND 4.0 International license.

a.

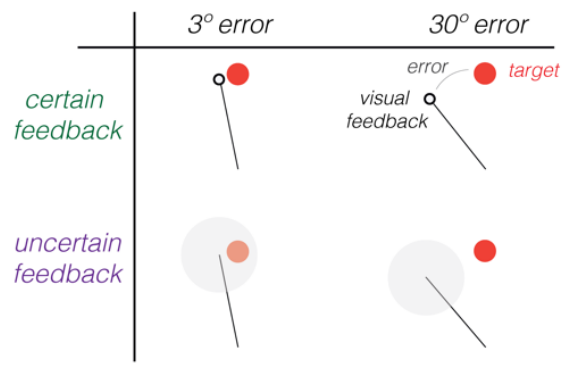

b.

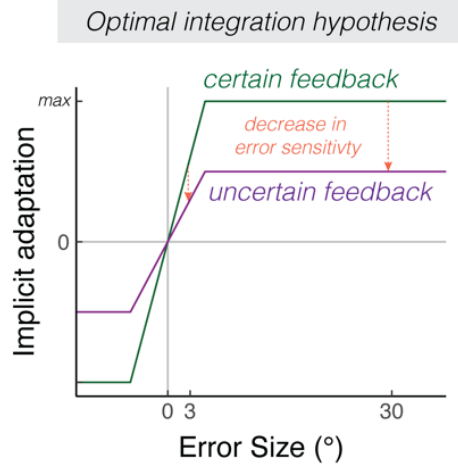

c. Mis-localization hypothesis

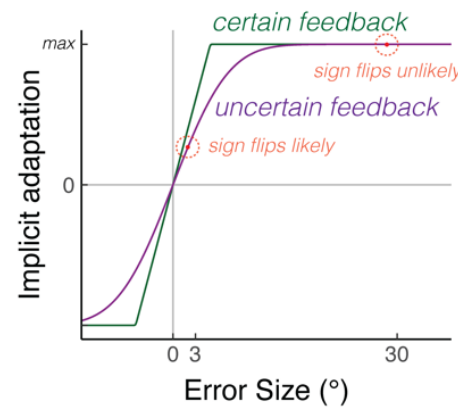

Figure 1. Illustrating two hypotheses for the effect of visual uncertainty on implicit motor adaptation. (a) In a typical visuomotor task, participants make reaching movements (black lines) towards a visual target (red dot). The reaching error can either be small $\left(3^{\circ}\right)$ or large $\left(30^{\circ}\right)$. The sensory prediction error - the difference between the predicted (i.e., the target) and perceived visual feedback location - can either be certain (black ring) or uncertain (grey region). When the sensory information is uncertain and the reaching error is small, it is possible for feedback to be mis-localized to the opposite side of the target. The predicted amount of implicit adaptation as a function of error size and visual uncertainty is plotted for the optimal integration hypothesis (b) and the mis-localization hypothesis (c). Both models assume that implicit adaptation is proportional to the size of the error when the error is small, but saturates when the error is large (Kim et al., 2018; Tsay, Kim, Haith, et al., 2021). Optimal integration posits that uncertainty will decrease the system's sensitivity to errors, an effect that will attenuate implicit adaptation for all error sizes. In contrast, the mis-localization posits that uncertainty will add variability to the perceived location of error without decreasing error sensitivity. For large errors, the perceived error always falls in the saturation zone, even when uncertainty is high. For small errors, uncertainty will increase the likelihood of errors being mislocalized on the wrong side of the target (see grey region in a), resulting in sign flips that, on average, attenuate implicit adaptation.

While the mis-localization hypothesis offers a parsimonious account for the interaction between error size and visual uncertainty, it remains to be seen whether this hypothesis also holds for uncertainty intrinsic to the sensorimotor system. Low vision - defined as vision loss that cannot be corrected with glasses, contacts, or surgery - induces intrinsic visual uncertainty often via ocular and retinal abnormalities (e.g., macular degeneration, glaucoma, retinitis pigmentosa, ocular albinism). As a result, individuals with low vision can have marked impairments in discriminating the color (Bowman, 1980), brightness (Legge, Parish, Luebker, \& Wurm, 1990), and the precise location of visual objects (Massof \& Fletcher, 2001; Pardhan, Gonzalez-Alvarez, \& Subramanian, 2012). These visual impairments are also associated with motor control deficits. For example, uncertainty about an object's location may result in slower and less accurate goal-directed movements (Cheong, Ling, \& Shehab, 2021; Endo et al., 2016; Jacko et al., 2000; Kotecha, O’Leary, Melmoth, Grant, \& Crabb, 2009; Lenoble, Corveleyn, Tran, Rouland, \& Boucart, 2019; Pardhan et al., 2012; Timmis \& Pardhan, 2012; Verghese, Tyson, Ghahghaei, \& Fletcher, 2016).

Here we asked how low vision impacts implicit adaptation, serving as a strong test to adjudicate between two hypotheses concerning how uncertainty is processed in the sensorimotor system. To address this question, we assessed individuals with low vision and matched controls on visuomotor tasks designed to isolate implicit adaptation and maintain tight control over the error size. Whereas the optimal integration hypothesis posits that intrinsic uncertainty induced by low vision would be associated with decreased sensitivity to error and attenuate implicit adaptation for all error sizes, the mis-localization hypothesis posits that low vision would only attenuate implicit adaptation in response to small errors, but not large errors. 


\section{Results}

Experiment 1: The impact of low vision on implicit motor adaptation for small and large errors

We recruited two groups of participants: Participants with low vision and matched controls ( $\mathrm{n}=20 / \mathrm{group}$, Table S1). Each participant performed a visuomotor adaptation task. Using our validated web-based platform (Tsay, Lee, Ivry, \& Avraham, 2021), we used a reaching task in which participants use their mouse or trackpad to move a cursor to intersect a visual target, with visual feedback presented throughout the movement. To measure implicit adaptation, we used a method in which the visual error is invariant, or "clamped" for the entire experiment, and varied the size of the error across conditions. Specifically, visual feedback always followed a trajectory that was either displaced $3^{\circ}$ (small error) or $30^{\circ}$ (large error) from the target (Figure 2a; 1a). By removing the contingency between the angular position of the feedback and the participant's actual movement, the error size is tightly controlled and kept constant throughout the entire experiment (Kim et al., 2018; Morehead, Taylor, Parvin, \& Ivry, 2017). Participants were asked to always reach directly to the target and ignore the feedback. Previous studies employing the clamped feedback task have elicited robust implicit changes in hand angle in the opposite direction of the cursor feedback (Avraham, Ryan Morehead, Kim, \& Ivry, 2021; Hutter \& Taylor, 2018; Liu, Jiang, Bi, \& Wei, 2021; Poh, Al-Fawakari, Tam, Taylor, \& McDougle, 2021; Tsay, Haith, Ivry, \& Kim, 2021; Tsay, Kim, Parvin, Stover, \& Ivry, 2021), despite the participants' phenomenal experience that their movements terminated close to the target (Tsay, Parvin, \& Ivry, 2020). 
bioRxiv preprint doi: https://doi.org/10.1101/2022.01.03.474829; this version posted January 4, 2022. The copyright holder for this preprint (which was not certified by peer review) is the author/funder, who has granted bioRxiv a license to display the preprint in perpetuity. It is made available under aCC-BY-NC-ND 4.0 International license.

a.

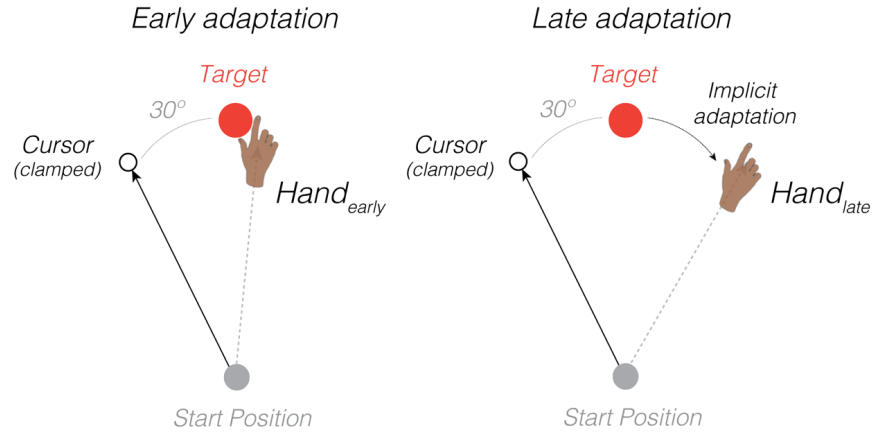

b.
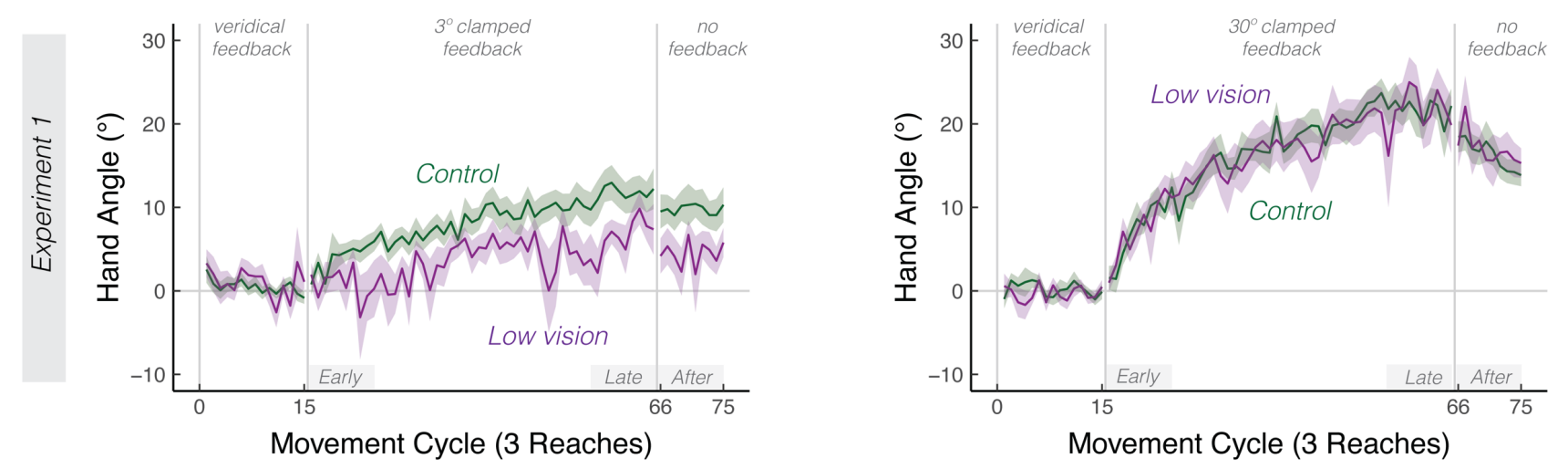

C.
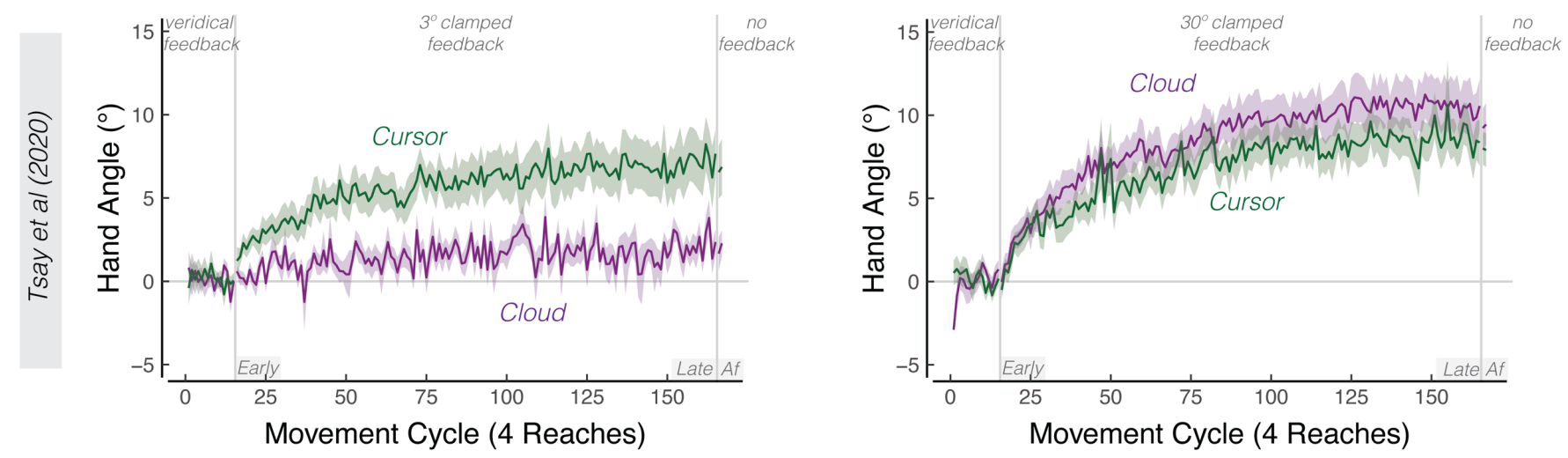

Figure 2: Intrinsic and extrinsic visual feedback uncertainty attenuate implicit adaptation in response to small, but not large errors. (a) Schematic of the clamped feedback task. The cursor feedback (white circle) follows a constant trajectory rotated relative to the target (red circle), independent of the position of the participant's hand. The rotation size remains invariant throughout the rotation block. The participant was instructed to move directly to the target and ignore the visual feedback. (b) Experiment 1 results. Mean time courses of hand angle for $3^{\circ}$ (left) and $30^{\circ}$ (right) visual clamped feedback, for both the low vision (dark magenta) and matched control (green) groups. (c) Tsay et al (2020) results. Mean time courses of hand angle for $3^{\circ}$ (left) and $30^{\circ}$ (right) visual clamped feedback, for both the cloud (dark magenta) and cursor (green) conditions. Hand angle is presented relative to the target $\left(0^{\circ}\right)$ during veridical feedback, clamped rotation feedback, and no-feedback aftereffect trials. Shaded region denotes SEM. Grey horizontal bars indicate early, late, and aftereffect phases of the experiment. 
After a baseline block with veridical feedback to familiarize the participants with the apparatus and basic trial structure, we presented clamped visual feedback either at $3^{\circ}$ or at $30^{\circ}$ away from the target for 50 cycles (150 trials). Consistent with prior studies, participants in both groups showed a gradual change in hand angle in the opposite direction of the clamped feedback, eventually hitting an asymptotic limit (Figure $2 \mathrm{~b}$ ). We summarize these changes in hand angle across four phases: baseline, early adaptation, late adaptation, and aftereffect (aftereffect was measured on trials after visual feedback was removed). For both groups, hand angles increased from baseline to early adaptation (control: $t_{72}=3.6, p<0.001, \beta=$ $5.0,[2.2,7.8], D_{z}=1.6$; low vision; $\left.t_{73}=3.6, p<0.001, \beta=5.1,[2.3,8.0], D_{z}=0.7\right)$, and continued to increase from early to late adaptation (control: $t_{193}=8.8, p<0.001, \beta=11.0$, [8.5, 13.4], $D_{z}=2.3$; low vision $t_{194}=8.0, p<$ $\left.0.001, \beta=10.0,[7.5,12.4], D_{z}=1.9\right)$. Hand angle decreased between late adaptation and the aftereffect phase, an effect assumed to reflect forgetting (i.e., decay back to baseline) when visual feedback is no longer provided (control: $t_{193}=$ $-3.6, p=0.005, \beta=-3.6,[-6.3,-1.4], D_{z}=1.1 ;$ low vision $t_{193}=-3.1, p=0.003, \beta=-3.9,[-6.3,-1.4], D_{z}=$ 1.1) (Joiner \& Smith, 2008; Krakauer, Ghez, \& Ghilardi, 2005; Morehead \& Smith, 2017). Comparing the left and right panels of Figures $2 b$ and $2 c$, the learning functions were higher when the error was $30^{\circ}$ compared to when the error was $3^{\circ}$ $\left(F_{1,194}=42.5, p<0.001, \eta_{p}^{2}=0.5\right)$, corroborating previous reports showing that implicit adaptation increases with the size of the error (Kim et al., 2018; Marko, Haith, Harran, \& Shadmehr, 2012).

We next turned to our main question, asking whether low vision selectively attenuates implicit adaptation in response to small errors, but not large errors, convergent with the interaction observed when the visual feedback is experimentally manipulated (Tsay, Avraham, et al., 2020). There was an interaction between group and error size $\left(F_{1,194}=14.0, p<\right.$ $\left.0.001, \eta_{p}^{2}=0.1\right)$ : Whereas the learning function between the two groups were indistinguishable in response to a $30^{\circ}$ error (Figure 2b, right; 3b), the learning function in the low vision group was attenuated compared to controls in response to a $3^{\circ}$ error (Figure 2b left; 3a). This assessment was confirmed by post-hoc t-tests, revealing that low vision was associated with attenuated implicit adaptation in response to the small error $\left(t_{38}=-2.3, p=0.03, \beta=-4.8,[-8.9,-0.6], D=0.7\right)$ but not the large error (control vs low vision: $t_{31}=0.3, p=0.76, \beta=0.6,[-3.6,4.8], D=0.1$ ).

While the session order $\left(3^{\circ}\right.$ or $\left.30^{\circ}\right)$ was fully counterbalanced across participants, one potential concern in a withinparticipant design of learning is that there may be an effect of transfer or interference between sessions (Avraham et al., 2021; Krakauer et al., 2005; Lerner et al., 2020). For instance, experiencing a $30^{\circ}$ clamped feedback in the first session may interfere with learning in the second session, resulting in attenuated learning. While this putative session order effect would likely apply to both groups, we opted to address this directly in a post-hoc analysis limited to the data obtained from session one. In this secondary analysis, the key interaction between group $\mathrm{x}$ error size was again significant $\left(F_{1,36}=8.5, p=\right.$ $\left.0.006, \eta_{p}^{2}=0.2\right)$, driven by a selective attenuating effect of low vision on small errors $\left(t_{22}=-2.1, p=0.04, \beta=\right.$ $-6.4,[-12.6,-0.2], D=0.7)$, but not large errors $\left(t_{11}=2.1, p=0.06, \beta=6.8,[-0.4,14.1], D=0.7\right.$; note the trend is in the opposite direction). 
These results converge with our previous in-laboratory study, in which sensory uncertainty was artificially increased using different cursor patterns (see Figure S1a,b for overview, single dot = certain feedback, cloud of dots = uncertain feedback) (Tsay, Avraham, et al., 2020). In the previous study, participants with typical vision showed attenuated implicit adaptation with uncertain feedback when the error size was $3^{\circ}$ but not when the error size was $30^{\circ}$ (Figure $2 \mathrm{c} \& 3 \mathrm{c}, \mathrm{d}$ ). The lower learning functions in Tsay et al (2020) compared to that of Experiment 1 presumably stems from the fact that we used trajectory feedback in the present study whereas Tsay et al. used endpoint feedback (Hinder, Riek, Tresilian, de Rugy, \& Carson, 2010; Taylor et al., 2014; van der Kooij, Brenner, van Beers, Schot, \& Smeets, 2013). Taken together, the results from both experiments suggest that visual uncertainty, either artificially manipulated or associated with low vision, does not conform to the optimal integration hypothesis. An optimal cue integrator would always down-weight uncertain feedback, attenuating implicit adaptation for all error sizes. However, implicit adaptation is only attenuated when the error size is small, an interaction consistent with the mis-localization hypothesis.

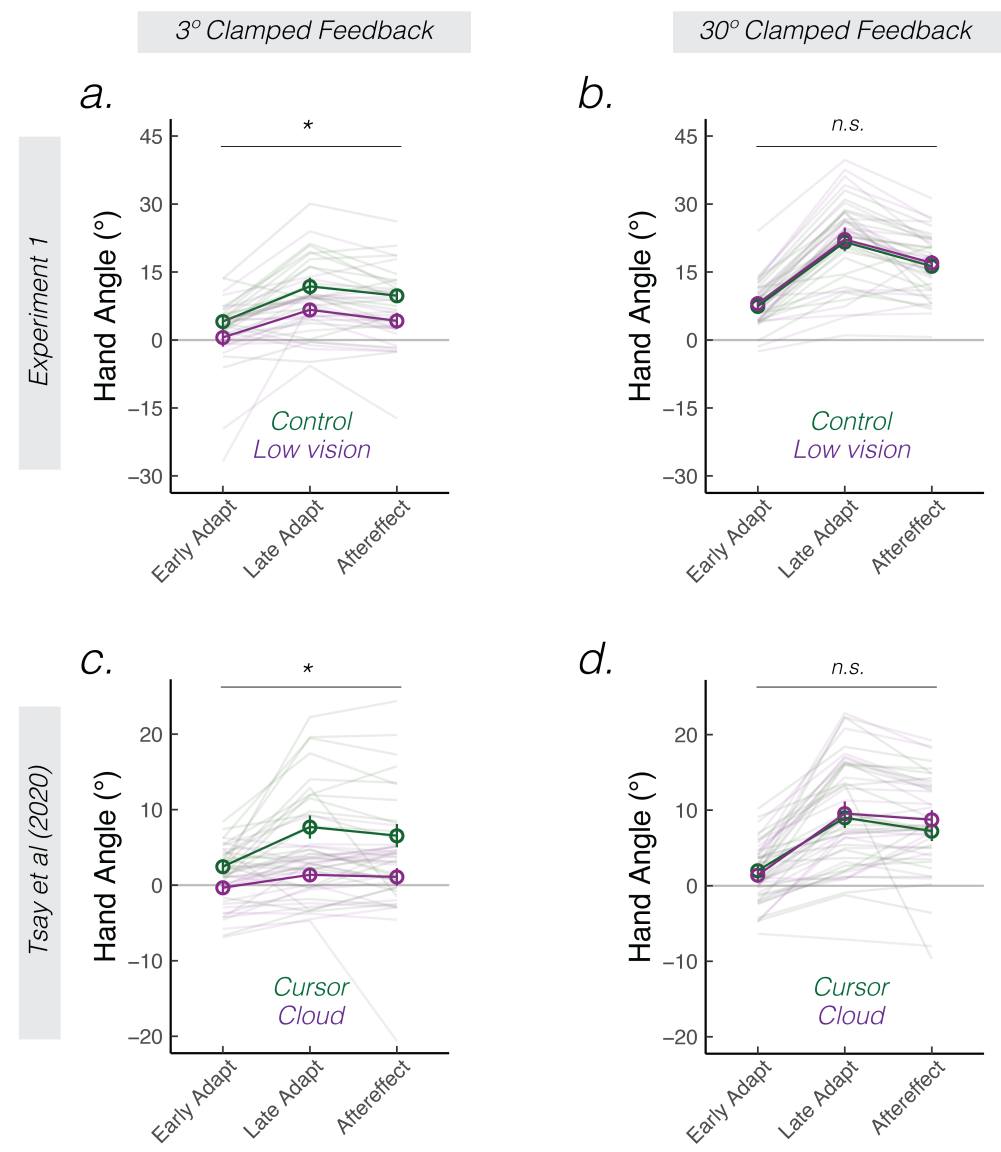

Figure 3: Visual uncertainty attenuates implicit adaptation in response to small, but not large errors. Mean hand angles \pm SEM during early and late phases of the rotation block, and during the no-feedback aftereffect block, for $3^{\circ}$ (a, c) and $30^{\circ}$ (b, d) clamped rotation sessions in Experiment 1 (top row) and Tsay et al (2020) (bottom row). n.s. denotes that the group comparison is not significant. $*$ denotes $\mathrm{p}<0.05$. Thin lines denote individual participants. 
Experiment 2: The impact of low vision on implicit motor aftereffects

The conclusion from Experiment 1 is predicated on the assumption that clamped feedback engages processes similar to those underlying implicit adaptation during standard visuomotor environments in which sensory feedback is contingent on motor behavior (Figure 4a). While the clamp method allows the experimenter to maintain tight control over error size and eliminates performance changes due to other learning processes (e.g., explicit re-aiming, see Morehead et al, 2017), Experiment 2 was designed to test if the findings from Experiment 1 would generalize to a standard visuomotor task. We opted to use a large rotation size $\left(45^{\circ}\right)$, since this is the critical condition where the optimal integration and mis-localization hypotheses make differential predictions. Specifically, the optimal integration hypothesis predicts a difference between the low vision and control groups, but the mis-localization hypothesis does not. To isolate the contribution of implicit adaptation, we focused on the change in hand angle observed during the aftereffect phase when visual feedback is removed after the rotation block.

Participants with low vision and matched controls ( $n=40$ /group, Table S2) participated in this study. Participants in the low vision (dark magenta) and control (green) groups exhibited gradual changes in hand angle in the opposite direction of the feedback (positive values), indicating that both groups were able to counter the perturbation (Figure $4 \mathrm{~b}$ ). That is, hand angles in both groups increased monotonically from baseline to early adaptation (control: $t_{227}=5.6, p<0.001, \beta=$ 7.1, [5.3, 11.0], $D_{z}=0.7$; low vision: $t_{220}=7.5, p<0.001, \beta=11.5,[8.5,14.5], D_{z}=1.2$ ), and from early to late adaptation (control: $t_{158}=12.2, p<0.001, \beta=23.9$, [20.0, 27.8], $D_{z}=2.7$; low vision: $t_{224}=9.1, p<0.001, \beta=$ $\left.21.1,[16.9,25.3], D_{z}=1.8\right)$. To minimize possible residual effects from explicit re-aiming, we reinforced the instructions at the start of the aftereffect block that the participant should reach directly to the target. Both groups showed a pronounced implicit motor aftereffect, with the heading angle offset from the target in the opposite direction of the rotation (control: $t_{222}=13.6, p<0.001, \beta=20.5,[17.5,23.5], D_{z}=2.7 ; \quad$ low $\quad$ vision: $\quad t_{226}=13.0, p<0.001, \beta=20.5,[16.1$, 22.6], $\left.D_{z}=1.8\right)$.

We then turned to our main question, asking whether participants with low vision show a deficit in implicit adaptation. The implicit motor aftereffects in low vision and control groups were indistinguishable $\left(t_{220}=-0.7, p=0.51, \beta=\right.$ $-1.4,[-5.6,2.8], D=0.1$ ), indicating that implicit adaptation did not differ between the two groups. Furthermore, there were also no significant group differences during early $\left(t_{219}=1.5, p=0.13, \beta=3.3,[-0.9,7.5], D=0.5\right)$ and late adaptation $\left(t_{221}=-1.3, p=0.19, \beta=-2.8,[-7.0,1.4], D=0.2\right)$. While this null effect should be interpreted with caution, the results of Experiment 2 provide converging evidence using a standard visuomotor task that implicit adaptation is not impaired in individuals with low vision when the error size is large. 
a.

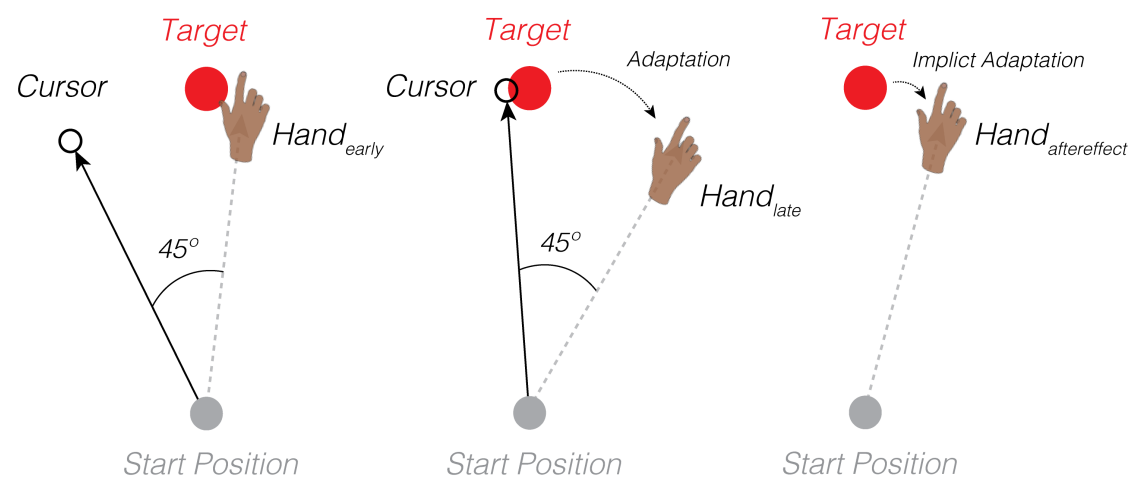

$b$.

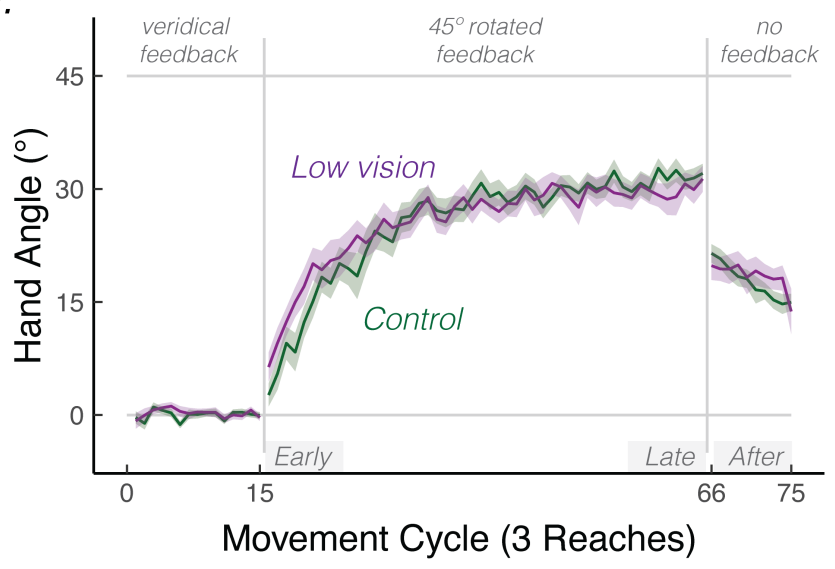

C.

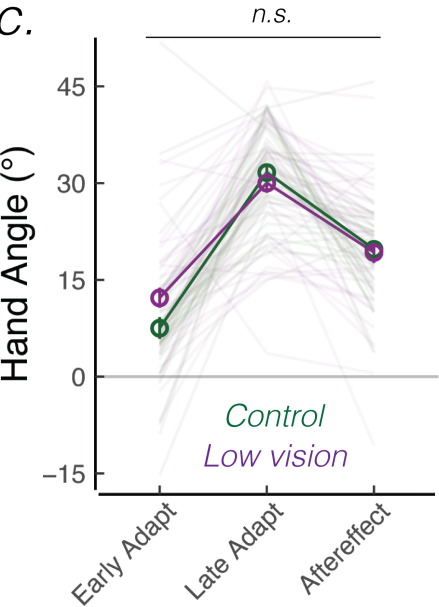

Figure 4: Visual uncertainty induced by low vision is not associated with reduced adaptation in response to a large $45^{\circ}$ visuomotor rotation. (a) Schematic of the visuomotor rotation task. The cursor feedback (white dot) was rotated $45^{\circ}$ with respect to the movement direction of the hand, with the sign of the rotation (clockwise or counterclockwise) counterbalanced across participants. Participants were instructed to move such that the cursor would intersect the target (red circle). Left, middle, and right panels display hand and cursor positions during early, late, and aftereffect phases of learning, respectively. (b) Mean time courses of hand angle for the low vision (purple) and control (green) groups. Hand angle is presented relative to the target $\left(0^{\circ}\right)$ during veridical feedback, rotation, and no-feedback aftereffect trials. Shaded region denotes SEM. Grey horizontal bars indicate early, late, and aftereffect phases of the experiment. (c) Mean hand angles \pm SEM during early and late phases of the rotation block, and during the no-feedback aftereffect block. n.s. denotes that the group comparison between low vision and controls is not significant across all phases. Thin lines denote individual participants. 


\section{Discussion}

Low vision can cause difficulty in discriminating the position of visual objects (Massof \& Fletcher, 2001; Timmis \& Pardhan, 2012). This impairment impacts motor performance, resulting in slower and less accurate goal-directed movements (Cheong et al., 2021; Endo et al., 2016; Jacko et al., 2000; Kotecha et al., 2009; Lenoble et al., 2019; Pardhan et al., 2012; Timmis \& Pardhan, 2012; Verghese et al., 2016). Here we asked how low vision impacts motor learning using a visuomotor adaptation task. The results revealed that low vision was associated with attenuated implicit adaptation when the sensory prediction error was small, but not when the error was large.

These findings adjudicate between two hypotheses concerning how uncertainty impacts sensorimotor adaptation. According to the optimal integration hypothesis, the motor system discounts, or down-weights the feedback signal, attenuating its response to feedback conveying an error (Burge et al., 2008; Samad et al., 2015; Shyr \& Joshi, 2021; van Beers, 2012; van Beers et al., 2002; Wei \& Körding, 2010). The optimal integration hypothesis predicts that visual uncertainty should attenuate implicit adaptation in response to all error sizes. In contrast, the mis-localization hypothesis posits that uncertainty does not alter the system's sensitivity to error, but instead adds variability to the distribution of the perceived error location (Tsay, Avraham, et al., 2020). By this view, small errors are sometimes mis-localized on the wrong side of a target, an effect that will increase with uncertainty, result in motor corrections in the wrong direction, and cumulatively attenuate implicit adaptation. The absence of sign flips when the error is large, even under conditions of uncertainty, would leave implicit adaptation to large errors unaffected.

The interaction between error size and uncertainty favors the mis-localization hypothesis, indicating that uncertainty induced by low vision impacts the perceived error location, rather than the system's sensitivity to error. Combined with our previous results in which visual uncertainty was artificially induced (Tsay, Avraham, et al., 2020), the mis-localization hypothesis accounts for the impact of uncertainty from the environment (e.g., a foggy day) as well as within the sensorimotor system (e.g., impairments in the retina, photoreceptors, optic nerve), both of which increase the likelihood that small errors will be occasionally mis-localized to the wrong side of a target.

Superficially, it would seem paradoxical to suggest that a clamped feedback signal would be perceived on the opposite side of its true position (relative to the target). Indeed, the participants are fully aware that the clamped feedback is invariant. However, this explicit knowledge about the perturbation does not impact the implicit adaptation system (Morehead et al., 2017). Evidence from a variety of experimental methods including clamped feedback indicate that adaptation is driven by an inflexible system that doggedly responds to a sensory prediction error to keep the sensorimotor system tightly calibrated (Bond \& Taylor, 2015; Kim et al., 2018; Morehead \& de Xivry, 2021; Morehead et al., 2017). The mis-localization hypothesis is consonant with this view in two ways: First, we assume that the perceived location of the error does not always correspond to the known location of the error, and it is the former that drives adaptation. Second, the sensitivity of the system to errors remains fixed despite uncertainty in the position of the visual feedback. A slight error experienced when reaching to pick up a cup of coffee with or without glasses will demand the same degree of correction. 
Previous work has shown that individuals with low vision move slower and make more errors when performing goaldirected movements (Kotecha et al., 2009; Pardhan, Gonzalez-Alvarez, \& Subramanian, 2011; Pardhan et al., 2012; Timmis \& Pardhan, 2012; Verghese et al., 2016). While these deficits are observed in people with both central and peripheral vision loss, reductions in central vision appear to be the key limiting factor (Pardhan et al., 2011, 2012). Central vision loss, resulting in lower acuity and worse contrast sensitivity, likely worsens the ability to precisely locate the intended visual target as well as respond to the sensory predictions conveying motor performance, an impairment that would be especially pronounced when the target and error are small (Legge et al., 1990; Tomkinson, 1974). Interestingly, in this study we did not observe strong associations between measures of visual ability and implicit adaptation (see Figure S3 c,f,i). However, future studies recruiting specific low vision subgroups would be essential to hone in on how different clinical impairments influence implicit adaptation.

Importantly, our results suggest that individuals with low vision exhibit intact error-based learning when the error can be detected. This finding may be exploited to enhance motor outcomes during rehabilitation (Tsay \& Winstein, 2020). For example, clinicians and practitioners could use non-visual feedback (e.g., auditory or tactile) to enhance the saliency and possibly reduce localization uncertainty of small visual error signals (Endo et al., 2016). For instance, haptic wearables have the potential to provide vibration, texture, slip, temperature, force, and proprioception sensations (Patel, Park, Bonato, Chan, \& Rodgers, 2012), which may help to improve motor control in both reaching and grasping for individuals with low vision. Moreover, rehabilitative specialists could provide explicit instructions to highlight the presence of small errors, such that individuals with low vision may be able to rely more on explicit re-aiming strategies to compensate for these errors (Merabet, Connors, Halko, \& Sánchez, 2012). Future work could examine which of these techniques is most effective to enhance motor learning when errors are small. 


\section{Methods}

\section{Ethics Statement}

All participants gave written informed consent in accordance with policies approved by the UC Berkeley's Institutional Review Board (Protocol Number: 2016-02-8439). Participation in the study was in exchange for monetary compensation.

\section{Participants}

Individuals with impaired vision that could not be corrected by glasses, contacts, or surgery (i.e., low vision) were recruited through UC Berkeley’s Meredith Morgan Eye Center and via word of mouth. Participants were screened using an online survey and excluded from participation if their self-reported visual acuity in their best-seeing eye was better than $20 / 30$ (i.e., $0.2 \log$ MAR). Participants also reported whether they had difficulty seeing road signs: Specifically, participants were prompted with a Likert scale from 1 (very blurry) to 7 (very clear). This functional measure strongly correlates with visual acuity (see Fig. S4). We also obtained survey information to determine if participants' low vision was related to peripheral vision loss and/or central vision loss, and whether their condition was congenital or acquired (Table 1, S1-2).

Across both experiments, 53 participants with low vision were recruited. The data from one participant were not included in the analyses because she did not complete both sessions in Experiment 2 . We thus analyzed the data of 52 unique participants with low vision: 12 participants completed only Experiment 1 (two sessions), 32 participants completed only Experiment 2 (one session), and 8 participants completed both experiments (three sessions). Sessions were spaced at least 24 hours apart to minimize any savings or interference (Avraham et al., 2021; Krakauer et al., 2005; Lerner et al., 2020). This amounted to a total of 80 online test sessions, with each session lasting approximately 45 minutes.

Sixty unique control participants who were recruited via Prolific, a website for online participant recruitment. Participants on Prolific have been thoroughly vetted through a screening procedure to ensure data quality. Participants were recruited to match the group of participants with low vision based on age, sex, handedness, and years of education. All control participants completed only one experiment, also amounting to 80 online test sessions, each lasting approximately 45 minutes.

The low vision and control groups did not differ in age $\left(\right.$ Exp $1: t_{38}=-0.5, p=0.64, \mu=-2.8,[-14.7,9.2], D=0.1$; $\left.\operatorname{Exp} 2: t_{78}=-1.8, p=0.08, \mu=-8.4,[-17.7,1.0], D=0.4\right)$, handedness $\left(\operatorname{Exp} 1: \chi^{2}(1)=0, p=1 ; \operatorname{Exp} 2: \chi^{2}(1)=\right.$ $0.44, p=0.36)$, years of education $\left(\operatorname{Exp} 1: t_{38}=-0.7, p=0.51, \mu=-0.5,[-2.0,1.0], D=0.2 ; \operatorname{Exp} 2: t_{78}=0.1, p=\right.$ 0.88, $\mu=0.1,[-0.9,1.1], D=0.0)$, or gender $\left(\operatorname{Exp} 1: \chi^{2}(1)=0, p=1 ; \operatorname{Exp} 2: \chi^{2}(1)=0.45, p=0.50\right)$. As expected, the low vision group reported significantly more visual impairments compared to the control group based on their selfreported difficulty with reading road signs $\left(\operatorname{Exp} 1: t_{38}=15.9, p<0.001, \mu=4.5,[3.9,5.0], D=5.1 ; \operatorname{Exp} 2: t_{77}=\right.$ $14.2, p<0.001, \mu=3.9,[3.3,4.4], D=3.2)$. 


\section{Apparatus}

Participants used their own computer to access a webpage hosted on Google Firebase. The task was created using the OnPoint platform (Tsay, Lee, Ivry, et al., 2021), and the task progression was controlled by JavaScript code running locally in the participant's web browser. The size and position of stimuli were scaled based on each participant's screen size/resolution (height $=920 \pm 180 \mathrm{px}$, width $=1618 \pm 433 \mathrm{px}$ ), which was automatically detected. For ease of exposition, the stimulus parameters reported reflect the average screen resolution in our participant population.

\section{Reaching task stimuli and procedure}

During the task, the participant performed small reaching movements by moving their computer cursor with their trackpad or mouse. The participant's mouse or trackpad sensitivity (gain) was not modified, but rather left at the setting the participant was familiar with. On each trial, participants made a center-out planar movement from the center of the workspace to a visual target. A white annulus (1\% of screen height: $0.24 \mathrm{~cm}$ in diameter) indicated the start location at the center of the screen, and a red circle ( $1 \%$ of screen height: $0.24 \mathrm{~cm}$ in diameter) indicated the target location. The radial distance of the target from the start location was $10 \mathrm{~cm}$ ( $40 \%$ of screen height). The target could appear at one of three directions from the center. Measuring angles counterclockwise and defining rightward as $0^{\circ}$, these directions were: $30^{\circ}$ (upper right quadrant), $150^{\circ}$ (upper left quadrant) and $270^{\circ}$ (straight down). Within each experiment, triads of trials (i.e., a cycle) consisted of one trial to each of the three targets. The order in which the three targets were presented were randomized within each cycle. Note that participants with color vision deficits could still do the task since position information also indicated the difference between the start location and target location.

At the beginning of each trial, participants moved their cursor to the start location at the center of their screen. Cursor position feedback, indicated by a white dot ( $0.6 \%$ of screen height: $0.1 \mathrm{~cm}$ in diameter), was provided when the cursor was within $2 \mathrm{~cm}$ of the start location (10\% of screen height). After maintaining the cursor in the start location for $500 \mathrm{~ms}$, the target appeared at one of three locations (see above). Participants were instructed to move rapidly to the target, attempting to "slice" through the target. If the movement was not completed within $750 \mathrm{~ms}$, the message "too slow" was displayed in red 20 pt. Times New Roman font at the center of the screen for $750 \mathrm{~ms}$.

Feedback during this movement phase could take one of the following forms: Veridical feedback, no-feedback, rotated noncontingent ("clamped") feedback, or rotated contingent feedback. During veridical feedback trials, the movement direction of the cursor was veridical with respect to the movement direction of the hand. That is, the cursor moved with their hand as would be expected for a normal computer cursor. During no-feedback trials, the cursor was extinguished as soon as the hand left the start annulus and remained off for the entire reach. During rotated clamped feedback trials (see Experiment 1 Methods, Figure 2a), the cursor moved at a specified angular offset relative to the position of the target, regardless of the movement direction of the hand - a manipulation shown to isolate implicit motor adaptation (Morehead et al., 2017; Tsay, Parvin, et al., 2020). With rotated contingent feedback (see Experiment 2 Methods; Figure 3a), the cursor moved at an 
angular offset relative to the position of the hand. For all feedback trials, the radial position of the cursor corresponded to that of the hand up to $10 \mathrm{~cm}$ (the radial distance of the target), at which point, the cursor position was frozen for $50 \mathrm{~ms}$, before disappearing. After completing a trial, participants moved the cursor back to the starting location. The visual cursor remained invisible until the participant moved within $2 \mathrm{~cm}$ of the start location, at which point the cursor appeared without any rotation.

\section{Experiment 1: The impact of low vision on implicit motor adaptation for small and large errors}

Participants with low vision and control participants ( $\mathrm{N}=20$ per group) were tested in two sessions, with clamped feedback used to induce implicit adaptation. In one session the clamp size was small $\left(3^{\circ}\right)$, and in the other it was large $\left(30^{\circ}\right)$. The two sessions were separated by at least 24 hours apart and the order and direction (clockwise or counterclockwise) of the clamped rotation were counterbalanced across individuals. Each session consisted of 75 cycles ( 225 trials total), distributed across three blocks: Baseline veridical feedback block (15 cycles), rotated clamped feedback (50 cycles), and a no-feedback aftereffect block (10 cycles).

Prior to the baseline block, the instruction "Move directly to the target as fast and accurately as you can" appeared on the screen. Prior to the clamped feedback block, the instructions were modified to read: "The white cursor will no longer be under your control. Please ignore the white cursor and continue to aim directly towards the target." To clarify the invariant nature of the clamped feedback, three demonstration trials were provided. On all three trials, the target appeared directly above the start location on the screen $\left(90^{\circ}\right.$ position) and the participant was told to reach to the left (demo 1$)$, to the right (demo 2), and downward (demo 3). On all three of these demonstration trials, the cursor moved in a straight line, $90^{\circ}$ offset from the target. In this way, the participant could see that the spatial trajectory of the cursor was unrelated to their own reach direction. Prior to the no-feedback aftereffect block, the participants were reminded to "Move directly to the target as fast and accurately as you can."

\section{Experiment 2: The impact of low vision on implicit motor aftereffects}

Low vision and control participants ( $\mathrm{N}=40$ per group) completed a visuomotor adaptation task consisting of three blocks of 75 cycles (225 trials total): Baseline veridical-feedback block (15 cycles), rotated contingent feedback block (50 cycles), and no-feedback aftereffect block (10 cycles). During the rotated feedback block, the direction of the cursor was rotated $45^{\circ}$ with respect to the direction of the participant's hand movement. The direction of the rotation (clockwise or counterclockwise) was counterbalanced across participants.

Prior to each baseline block, the instruction "Move directly to the target as fast and accurately as you can" appeared on the screen. Prior to the rotation block, a new instruction message was presented: "Your cursor will now be rotated by a certain amount. To continue hitting the target with your cursor, you will have to aim away from the target." Prior to the no-feedback aftereffect block, the participants were instructed to "Move directly to the target as fast and accurately as you can." 
Attention and instruction checks

\section{Data Analysis} 196 - 225).

It is difficult in online studies to verify that participants fully attend to the task. To address this issue, we sporadically instructed participants to make specific keypresses: "Press the letter 'b' to proceed." If participants failed the make an accurate keypress, the experiment was terminated. These attention checks were randomly introduced within the first 50 trials of the experiment. We also wanted to verify that the participants understood the clamped rotation manipulation. To this end, we included one instruction check after the three demonstration trials: "Identify the correct statement. Press 'a': I will aim away from the target and ignore the white dot. Press ' $b$ ': I will aim directly towards the target location and ignore the white dot." The experiment was terminated if participants failed to make the correct response (i.e., press 'b').

The primary dependent variable of reach performance was hand angle, defined as the angle of the hand relative to the target when movement amplitude reached a $10 \mathrm{~cm}$ radial distance from the start position. Specifically, we measured the angle between a line connecting the start position to the target and a line connecting the start position to the hand. Given that there is little generalization of learning between target locations spaced more than $120^{\circ}$ apart (Krakauer et al., 2005; Morehead et al., 2017), the data are graphed by cycles.

Outlier responses were defined as trials in which the hand angle deviated by more than three standard deviations from a moving 5-trial window or if the hand angle was greater than $90^{\circ}$ from the target (average percent of trials removed per participant in $\operatorname{Exp} 1$, control $=2.2 \pm 6.2 \%$, low vision $=6.1 \pm 13.0 \%$; Exp 2, control $=3.1 \pm 4.6 \%$, low vision $=5.2 \pm 10.2 \%$ )

We defined three summary measures of learning: Early adaptation, late adaptation, and aftereffect. Early adaptation was operationalized as the mean hand angle over the first 10 movement cycles of the rotation block (trials 46 - 75). Late adaptation was defined as the mean hand angle over the last 10 movement cycles of the rotation block (trials 166 - 195). The aftereffect was operationalized as the mean angle over all movement cycles of the no-feedback aftereffect block (trials

These data were submitted to a linear mixed effect model, with hand angle measures as the dependent variable. In Experiment 1, we included Experiment Phase (Early adaptation, Late adaptation, Aftereffect), Group (low vision or control), and Error Size $\left(3^{\circ}, 30^{\circ}\right)$ as fixed effects and Participant ID as a random effect. A priori, we hypothesized that the low vision group would differ from the controls in their response to the small errors. Reaction time was included as a covariate in the analysis since RT was greater in the low vision group compared to the control group (RT: $t_{25}=3.3, p=0.002, \mu=$ $157.9,[60.7,255.1], D=1.1)$. RT was defined as the interval between target presentation to the start of movement (operationalized as time at which the hand movement exceeded $1 \mathrm{~cm})$. Movement time $(\mathrm{MT}=$ the time between the start of the movement and when the radial distance of the movement reached $10 \mathrm{~cm}$ ) was not included as a covariate since MT did 
not differ between groups (MT: $t_{36}=0.3, p=0.79, \mu=11.3,[-74.1,96.6], D=0.1$ ). We note that the results are similar if MT is included as a covariate.

In Experiment 2, the main prediction centered on a null effect of Group over all Phases for only one large error size. As such, we included Experiment Phase and Group as two fixed effects (with the Group x Phase interaction included) and Participant ID as a random effect. Because we observed group differences in RT and MT (RT: $t_{78}=-4.5, p<0.001, \mu=$ 177.7, [-255.7, -99.7], $D=1.0$; MT: $\left.t_{78}=-4.2, p<0.001, \mu=-193.4,[-285.4,-101.4], D=0.9\right)$, both variables were included as covariates.

We employed F-tests with the Satterthwaite method to evaluate whether the coefficients (i.e., beta values) obtained from the linear mixed effects model were statistically significant ( $\mathrm{R}$ functions: 1mer, lmerTest, anova). Pairwise post-hoc t-tests (two-tailed) were used to compare hand angle measures between the low vision and control groups (R function: emmeans). P-values were adjusted for multiple comparisons using the Tukey method. The degrees of freedom were also adjusted when the variances between groups were not equal. 95\% confidence intervals for group comparisons (t-tests) and beta values obtained from the linear mixed effects model are reported in squared brackets. Standard effect size measures are also provided ( $D$ for between-participant comparisons; $D_{z}$ for within-participant comparisons; $\eta_{p}^{2}$ for between-subjects ANOVA) (Lakens, 2013). 


\section{Acknowledgements}

We thank Phoebe Lo for her assistance in data collection.

\section{Supplemental Analyses}

\section{Experiment 1}

Since the low vision group on average initiated movements slower than the control group (see Methods), we added RT as a covariate in our analyses. Implicit adaptation was modulated by $\mathrm{RT}\left(F_{1,150}=5.4, p=0.02, \eta_{p}^{2}=0.0\right)$ : For both groups, longer RTs were associated with lower asymptotic levels of adaptation. This may reflect reduced levels attention and motivation, or perhaps increased caution in making goal-directed movements (Shadmehr \& Ahmed, 2020).

We also explored whether various subgroups of the participants with low vision exhibited differences in implicit adaptation. As shown in Figure S2, there were no appreciable differences between participants who moved fast or slow (Figure S2a,e; median split: $F_{1,45}=0.1, p=0.73, \eta_{p}^{2}=0.0$ ), with and without central vision loss (Figure S2b,f; $F_{1,44}=0.0, p=$ $0.94, \eta_{p}^{2}=0.0$ ), with and without peripheral vision loss (Figure S2c,g; $F_{1,43}=0.4, p=0.55, \eta_{p}^{2}=0.0$ ), or early vs late onset of low vision (Figure S2d,h; $F_{1,43}=0.2, p=0.69, \eta_{p}^{2}=0.0$ ). In sum, we did not identify additional features amongst individuals in the low vision group that impacted implicit adaptation in Experiment 1.

Furthermore, neither the participants' self-reports of visual acuity (Figure S3a, d) nor ability to perceive road signs (Figure $\mathrm{S} 3 \mathrm{~b}, \mathrm{e})$ correlated with implicit adaptation. The absence of a correlation for the small error condition may seem strange: Considering our hypothesis that reduced implicit adaptation in this condition arises from misperception of the feedback location, one might predict that lower acuity would be associated with less adaptation. However, while visual acuity as measured in the clinic focuses on fine-detail visual discrimination (e.g., reading), this aspect of vision may not be an essential aspect of visual uncertainty in our task in which both the feedback cursor and the target are fairly large on the computer monitor (Table S1, Figure S3c,d). Instead, features such as contrast sensitivity may be important for distinguishing the location of the feedback and the target on the black background.

\section{Experiment 2}

We included RT and MT as covariates in the analyses since the low vision group had longer RTs and MTs than the control group (see Methods). There was no main effect of $\mathrm{RT}\left(F_{1,104}=1.4, p=0.24, \eta_{p}^{2}=0.0\right)$. However, in both groups, the amount of adaptation was modulated by movement time $\left(F_{1,125}=11.5, p<0.001, \eta_{p}^{2}=0.1\right)$ : Participants who took a longer time to move also exhibited greater changes in hand angle. This effect of MT may arise from a subset of participants who made feedback corrections mid-movement. A finer examination of subgroups with low vision also revealed a main effect of MT (median split: $\left.F_{1,105}=6.3, p=0.01, \eta_{p}^{2}=0.0\right)$ as well an interaction between MT $\mathrm{x}$ Phase $\left(F_{2,76}=3.5, p=\right.$ 
$0.03, \eta_{p}^{2}=0.1$ ). As shown in Figure S2i, post-hoc t-tests showed that this interaction was driven by group differences only in early adaptation $\left(t_{105}=-2.5, p=0.01, \mu=-7.9,[-13.7,-2.0], D=0.9\right)$. There were no group differences during either late adaptation $\left(t_{105}=0.3, p=0.76, \mu=1.0,[-5.4,7.3], D=0.1\right)$ or in the aftereffect phase $\left(t_{105}=0.5, p=\right.$ $0.64,=1.5,[-5.3,8.2], D=0.1)$.

In terms of other features of low vision, we observed no differences between participants with or without peripheral vision loss (Figure S2k; $F_{1,38}=0.4, p=0.52, \eta_{p}^{2}=0.0$ ) and early or late disease onset (Figure S21; $F_{1,38}=0.6, p=0.81, \eta_{p}^{2}=$ $0.0)$. However, as shown in Figure $\mathrm{S} 2 \mathrm{j}$, there was a marginal effect of central vision loss $\left(F_{1,38}=3.4, p=0.07, \eta_{p}^{2}=0.1\right)$ as well as a marginal interaction between central vision loss and experimental phase $\left(F_{2,76}=2.7, p=0.07, \eta_{p}^{2}=0.1\right)$. Post-hoc t-tests suggest that this interaction was driven by between participants differences only in the late adaptation phase $\left(t_{108}=2.6, p=0.009, \mu=8.4,[2.2,14.5], D=0.9\right)$, and not during early adaptation $\left(t_{108}=-0.3, p=0.73, \mu=\right.$ $-1.1,[-7.2,5.0], D=0.1)$ and aftereffect phases $\left(t_{108}=1.4, p=0.16, \mu=4.5,[-3.0,11.9], D=0.4\right)$. This selective effect of central vision loss during late adaptation may be attributed to a difficulty in perceiving the small difference between the cursor and target position since the participants in this late phase of learning may have already compensated for most of the $45^{\circ}$ rotation. Similar to Experiment 1, neither visual acuity (Figure S3g) nor perceptibility of road signs (Figure S3h) correlated significantly with implicit adaptation. As for Experiment 1, a breakdown of aftereffect size by clinical diagnosis is shown in Figure S3i. 
a.

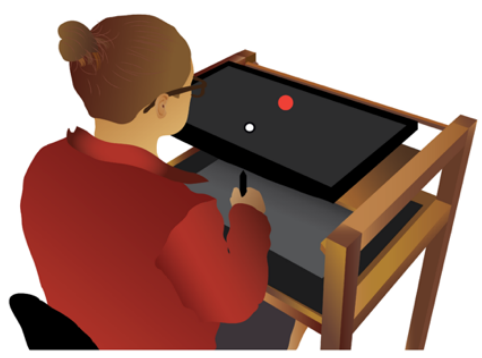

b.

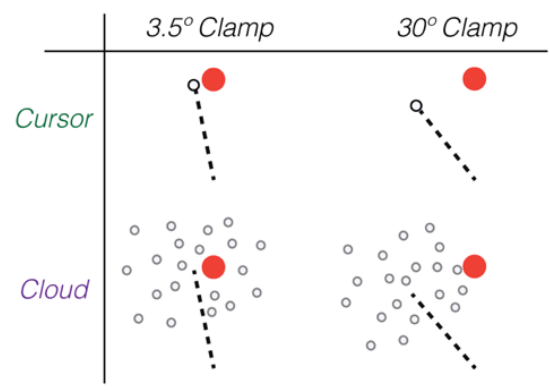

Figure S1: Experimental apparatus and design in Tsay et al (2020). (a) Experimental apparatus. All participants performed centerout reaches on a horizontal surface while seated at a custom-made tabletop. Participants held a modified air hockey "paddle" that contained a stylus and moved this device across a digitizing tablet. An LCD screen was suspended above the tablet. (b) Experimental design. Participants made reaching movements towards a visual target (blue circle). Feedback was provided as either a small $3^{\circ}$ visual clamp or large $30^{\circ}$ visual clamp, paired with cursor (certain feedback) or cloud feedback (uncertain feedback). There were four groups of participants in a $2 \times 2$ factorial design. 
bioRxiv preprint doi: https://doi.org/10.1101/2022.01.03.474829; this version posted January 4, 2022. The copyright holder for this preprint (which was not certified by peer review) is the author/funder, who has granted bioRxiv a license to display the preprint in perpetuity. It is made available under aCC-BY-NC-ND 4.0 International license.
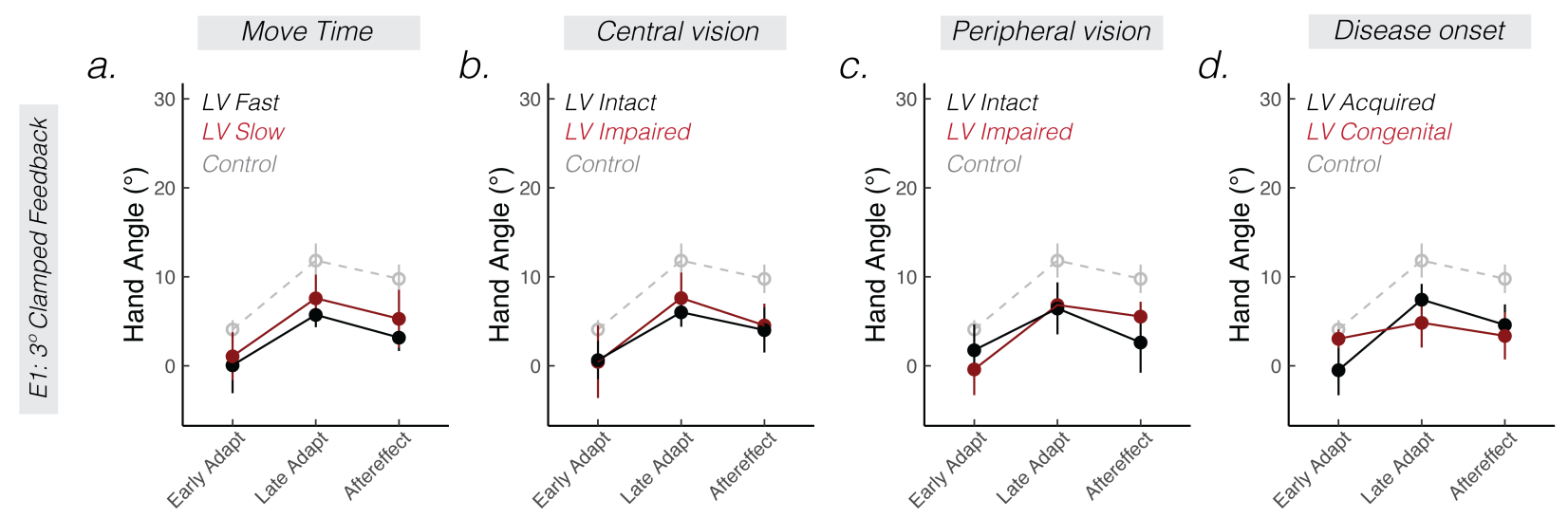

e.

f.
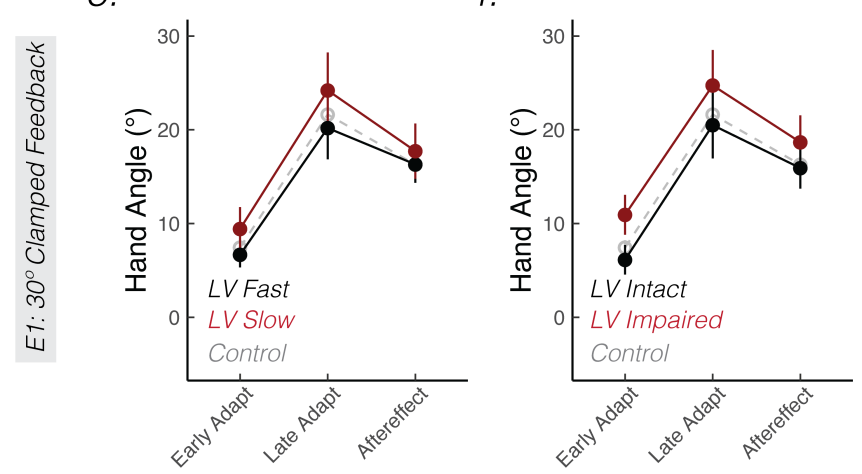

g.

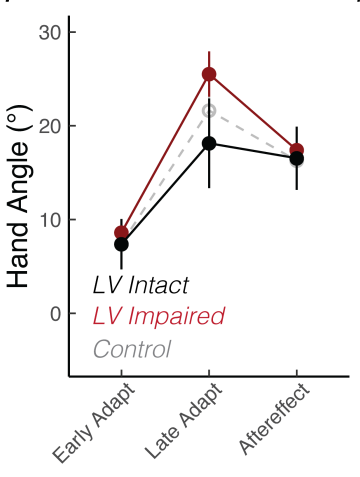

$h$.
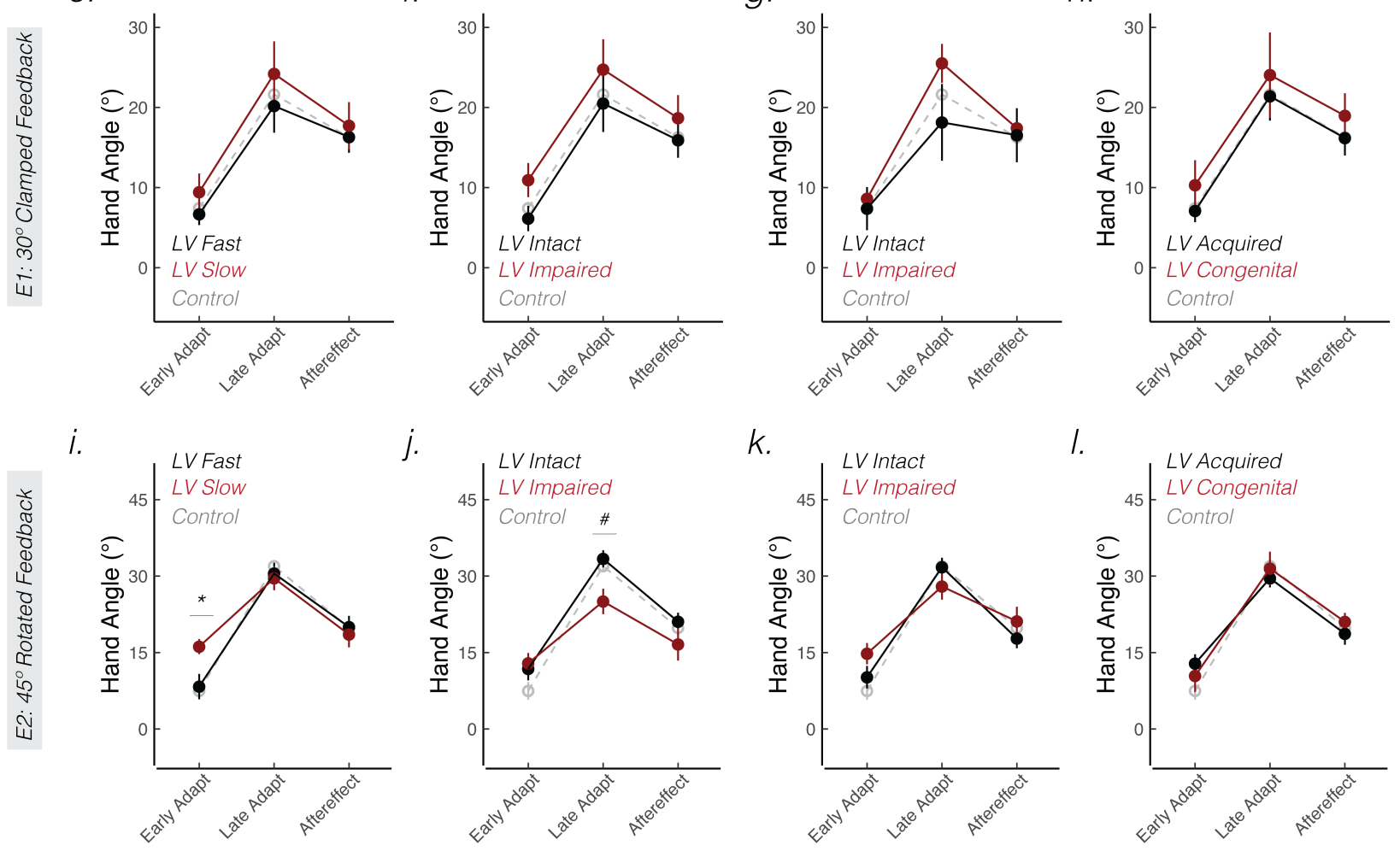

Figure S2: Low vision subgroup analyses. Mean hand angles \pm SEM during early and late phases of the rotation block, and during the no-feedback aftereffect block of Experiment $1(\mathbf{a}-\mathbf{h})$ and Experiment $2(\mathbf{i}-\mathbf{l})$. Each column divides the low vision group based on a different performance or clinical variable: Movement time (a, e, i), central vision loss $(\mathbf{b}, \mathbf{f}, \mathbf{j})$, peripheral vision loss $(\mathbf{c}, \mathbf{g}, \mathbf{k})$, or disease onset $(\mathbf{d}, \mathbf{h}, \mathbf{l})$. The control group is shown in grey dashed lines. ${ }^{*}$ denotes $\mathbf{p}<0.05 .{ }^{\#}$ denotes $\mathbf{p}<0.10$. 
bioRxiv preprint doi: https://doi.org/10.1101/2022.01.03.474829; this version posted January 4, 2022. The copyright holder for this preprint (which was not certified by peer review) is the author/funder, who has granted bioRxiv a license to display the preprint in perpetuity. It is made available under aCC-BY-NC-ND 4.0 International license.

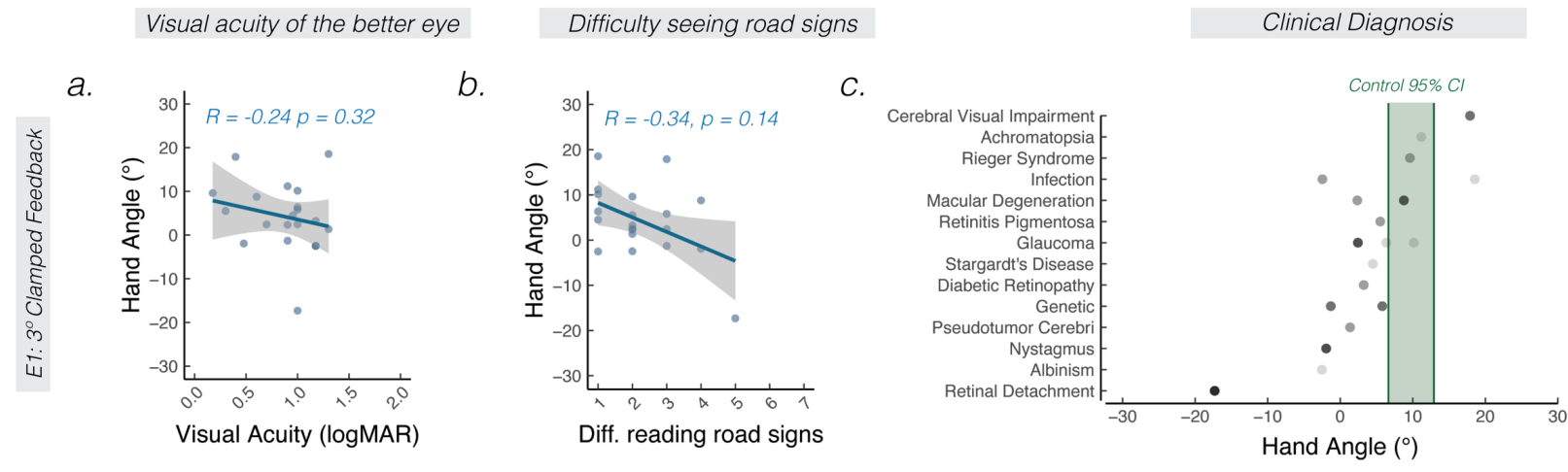

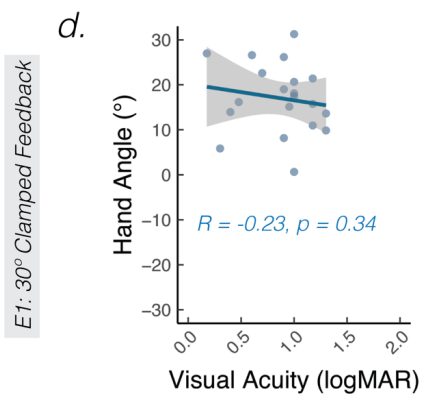

e.

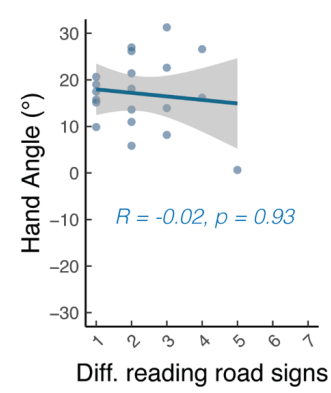

h.
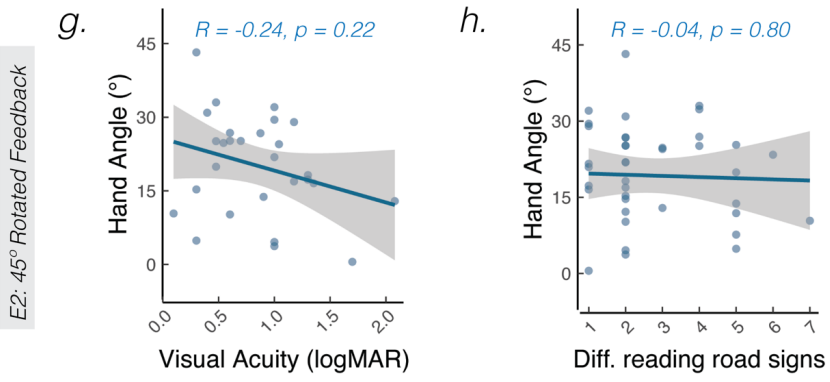

f.

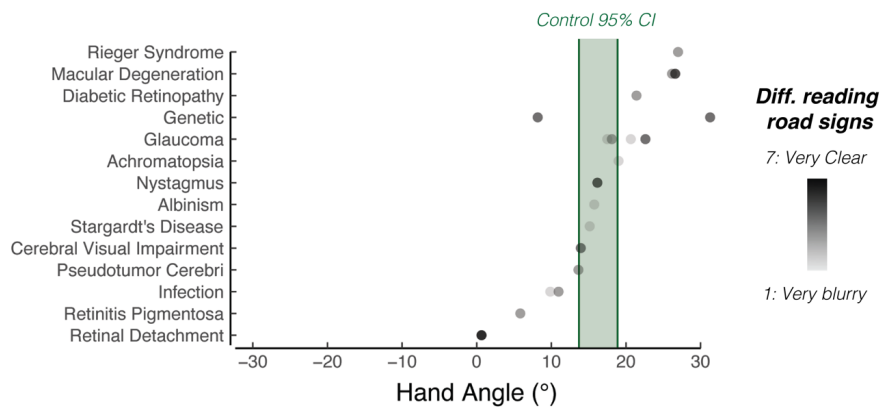

Figure S3: The effect of visual acuity and clinical diagnosis on motor aftereffects. Correlation between visual acuity of the less impaired eye and motor aftereffects in Experiment $1(\mathbf{a}, \mathbf{d})$ and Experiment 2 (g). Correlation between how clearly participants report seeing road signs $(1=$ very clear; 7 = very blurry) and motor aftereffects in Experiment 1 (b, e) and Experiment 2 (h). Solid line indicates mean regression line and shaded region indicates SEM. The Spearman correlation is noted by $R$. (c, $\mathbf{f}, \mathbf{i})$ Mean aftereffects sorted by clinical diagnoses involving low vision. Shading of the dot indicates how well participants report seeing road signs (light shading $=$ road signs are very blurry; dark shading $=$ road signs are very clear). The $95 \%$ confidence interval for the control group is indicated by the green shaded region. 


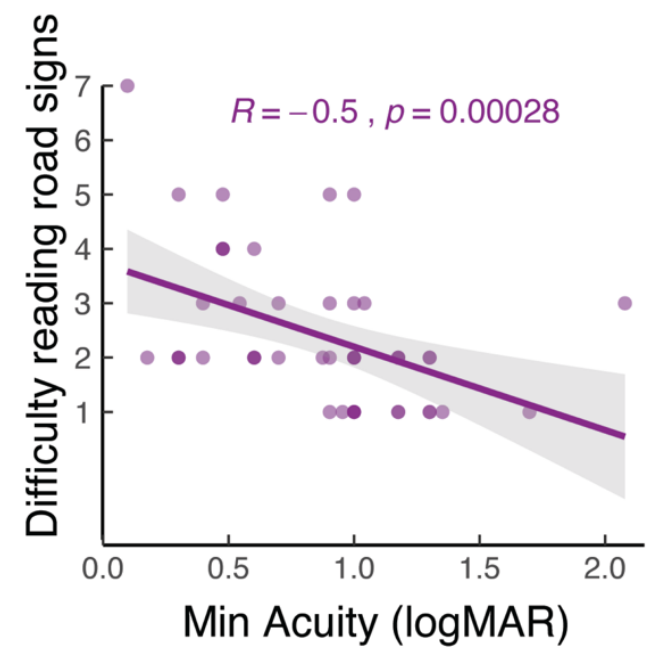

Figure S4: Participants who have lower visual acuity in their less impaired eye report more difficulty in reading road signs. Participants used a Likert scale from 1 (very blurry) to 7 (very clear) to indicate how well they were able to read road signs. Solid line indicates mean regression line and shaded region indicates SEM. The Spearman correlation is noted by $R$. Each data point denotes an individual participant (pooled across Experiments 1 and 2). 
bioRxiv preprint doi: https://doi.org/10.1101/2022.01.03.474829; this version posted January 4, 2022. The copyright holder for this preprint (which was not certified by peer review) is the author/funder, who has granted bioRxiv a license to display the preprint in perpetuity. It is made available under aCC-BY-NC-ND 4.0 International license.

\begin{tabular}{|c|c|c|c|c|c|c|c|c|c|c|}
\hline \# & Age & YOE & Hand & Gender & $\begin{array}{l}\text { Low vision } \\
\text { diagnosis }\end{array}$ & $\begin{array}{l}\text { Visual acuity } \\
\text { in better eye }\end{array}$ & $\begin{array}{l}\text { Seeing road } \\
\text { signs }\end{array}$ & $\begin{array}{l}\text { Peripheral } \\
\text { visual field }\end{array}$ & $\begin{array}{c}\text { Central } \\
\text { visual field }\end{array}$ & $\begin{array}{c}\text { Low vision } \\
\text { onset }\end{array}$ \\
\hline $1^{\#}$ & 31 & 18 & $\mathrm{R}$ & $\mathrm{M}$ & Retinitis Pigmentosa & 0.3 & 2 & $x$ & $\checkmark$ & $\mathrm{A}$ \\
\hline $2^{\#}$ & 34 & 22 & $\mathrm{R}$ & $\mathrm{M}$ & Achromatopsia & 0.9 & 2 & $\checkmark$ & $\checkmark$ & $\mathrm{C}$ \\
\hline $3^{\#}$ & 60 & 18 & $\mathrm{R}$ & $\mathrm{D}$ & Retinitis Pigmentosa & 1.3 & 1 & $\times$ & $\checkmark$ & $\mathrm{A}$ \\
\hline $4^{\#}$ & 86 & 16 & $\mathrm{R}$ & $\mathrm{M}$ & Glaucoma & 1.0 & 2 & $\times$ & $\checkmark$ & A \\
\hline $5^{\#}$ & 70 & 18 & $\mathrm{R}$ & $\mathrm{F}$ & Macular Degeneration & 0.9 & 5 & $\checkmark$ & $\times$ & A \\
\hline $6^{\#}$ & 34 & 14 & $\mathrm{R}$ & $\mathrm{F}$ & Pseudotumor Cerebri & 1.7 & 1 & $x$ & $\times$ & A \\
\hline $7^{\#}$ & 61 & 18 & A & $\mathrm{F}$ & Rieger Syndrome & 0.2 & 4 & $\times$ & $\checkmark$ & A \\
\hline $8^{\#}$ & 26 & 16 & $\mathrm{R}$ & $\mathrm{F}$ & Charcot Marie Tooth & 0.9 & 4 & $\checkmark$ & $\checkmark$ & $\mathrm{A}$ \\
\hline 9 & 86 & 16 & $\mathrm{R}$ & $\mathrm{M}$ & Glaucoma & 1 & 1 & $\times$ & $\checkmark$ & A \\
\hline 10 & 55 & 16 & $\mathrm{R}$ & $\mathrm{M}$ & Stargardt's Disease & 1 & 1 & $x$ & $\times$ & A \\
\hline 11 & 37 & 22 & A & $\mathrm{F}$ & Retinal Detachment & 1 & 5 & $\checkmark$ & $\checkmark$ & A \\
\hline 12 & 29 & 18 & $\mathrm{R}$ & $\mathrm{M}$ & Glaucoma & 0.7 & 3 & $\times$ & $\checkmark$ & A \\
\hline 13 & 59 & 16 & $\mathrm{R}$ & $\mathrm{M}$ & Diabetic Retinopathy & 1.7 & 2 & $x$ & $\checkmark$ & A \\
\hline 14 & 31 & 12 & $\mathrm{R}$ & $\mathrm{F}$ & $\begin{array}{c}\text { Glaucoma, Deprivation } \\
\text { Amblyopia }\end{array}$ & 1 & 1 & $x$ & $\checkmark$ & $\mathrm{C}$ \\
\hline 15 & 33 & 18 & $\mathrm{R}$ & $\mathrm{F}$ & Genetic/Developmental & 1 & 3 & $\checkmark$ & $\times$ & $\mathrm{C}$ \\
\hline 16 & 24 & 16 & $\mathrm{R}$ & $\mathrm{F}$ & Albinism & 1.7 & 1 & $x$ & $\times$ & $\mathrm{C}$ \\
\hline 17 & 78 & 22 & $\mathrm{R}$ & $\mathrm{F}$ & Macular Degeneration & 0.6 & 4 & $\checkmark$ & $\times$ & A \\
\hline 18 & 28 & 18 & $\mathrm{R}$ & $\mathrm{F}$ & Nystagmus & 0.5 & 4 & $\checkmark$ & $\checkmark$ & $\mathrm{C}$ \\
\hline 19 & 60 & 18 & A & $\mathrm{F}$ & $\begin{array}{l}\text { Cerebral Visual } \\
\text { Impairment } \\
\end{array}$ & 0.4 & 3 & $\times$ & $\checkmark$ & $\mathrm{A}$ \\
\hline 20 & 60 & 18 & $\mathrm{R}$ & $\mathrm{F}$ & Infection & 1.7 & 2 & $\checkmark$ & $\times$ & $\mathrm{C}$ \\
\hline
\end{tabular}

Table S1: Experiment 1 participants with low vision. Gender was self-reported as male (M), female (F), or declined to specify (D). Handedness was reported as right (R), left (L), or unknown (U). Self-reports of visual acuity of the better seeing eye (logMAR) and peripheral/central visual field loss are provided. $\checkmark$ denotes intact and $\times$ denotes impaired function. Disease onset was self-reported as congenital (C), acquired (A), or unknown (U). ${ }^{*}$ denotes individual who also participated in Experiment 2. 
bioRxiv preprint doi: https://doi.org/10.1101/2022.01.03.474829; this version posted January 4, 2022. The copyright holder for this preprint (which was not certified by peer review) is the author/funder, who has granted bioRxiv a license to display the preprint in perpetuity. It is made available under aCC-BY-NC-ND 4.0 International license.

\begin{tabular}{|c|c|c|c|c|c|c|c|c|c|c|}
\hline$\#$ & Age & YOE & Hand & Gender & $\begin{array}{c}\text { Low vision } \\
\text { diagnosis }\end{array}$ & $\begin{array}{c}\text { Visual acuity in } \\
\text { better eye }\end{array}$ & $\begin{array}{c}\text { Seeing road } \\
\text { signs }\end{array}$ & $\begin{array}{l}\text { Peripheral } \\
\text { visual field }\end{array}$ & $\begin{array}{c}\text { Central } \\
\text { visual field }\end{array}$ & $\begin{array}{c}\text { Low vision } \\
\text { onset }\end{array}$ \\
\hline $1^{\#}$ & 31 & 18 & $\mathrm{R}$ & $\mathrm{M}$ & Retinitis Pigmentosa & 0.3 & 2 & $\times$ & $\checkmark$ & $\mathrm{A}$ \\
\hline $2^{\#}$ & 34 & 22 & $\mathrm{R}$ & $\mathrm{M}$ & Achromatopsia & 0.9 & 2 & $\checkmark$ & $\checkmark$ & $\mathrm{C}$ \\
\hline $3^{\#}$ & 60 & 18 & $\mathrm{R}$ & $\mathrm{D}$ & Retinitis Pigmentosa & 1.3 & 1 & $x$ & $\checkmark$ & $\mathrm{A}$ \\
\hline $4^{\#}$ & 86 & 16 & $\mathrm{R}$ & $\mathrm{M}$ & Glaucoma & 1.0 & 2 & $x$ & $\checkmark$ & $\mathrm{A}$ \\
\hline $5^{\#}$ & 70 & 18 & $\mathrm{R}$ & $\mathrm{F}$ & $\begin{array}{c}\text { Macular } \\
\text { Degeneration }\end{array}$ & 0.9 & 5 & $\checkmark$ & $x$ & A \\
\hline $6^{\#}$ & 34 & 14 & $\mathrm{R}$ & $\mathrm{F}$ & Pseudotumor Cerebri & 1.7 & 1 & $\times$ & $\times$ & $\mathrm{A}$ \\
\hline $7^{\#}$ & 61 & 18 & $\mathrm{~A}$ & $\mathrm{~F}$ & Rieger Syndrome & 0.2 & 4 & $\times$ & $\checkmark$ & $\mathrm{A}$ \\
\hline $8^{\#}$ & 26 & 16 & $\mathrm{R}$ & $\mathrm{F}$ & Charcot Marie Tooth & 0.9 & 4 & $\checkmark$ & $\checkmark$ & $\mathrm{A}$ \\
\hline 9 & 75 & 18 & $\mathrm{R}$ & $\mathrm{F}$ & $\begin{array}{c}\text { Macular } \\
\text { Degeneration } \\
\text { Keratoconus } \\
\end{array}$ & $\mathrm{U}$ & 5 & $\checkmark$ & $\checkmark$ & A \\
\hline 10 & 78 & 20 & $\mathrm{R}$ & $\mathrm{M}$ & Glaucoma & 0.6 & 2 & $\checkmark$ & $\checkmark$ & $\mathrm{A}$ \\
\hline 11 & 30 & 16 & $\mathrm{R}$ & $\mathrm{F}$ & Stargardt's Disease & 0.6 & 2 & $\checkmark$ & $x$ & $\mathrm{~A}$ \\
\hline 12 & 70 & 18 & $\mathrm{R}$ & $\mathrm{F}$ & Glaucoma & 0.4 & 2 & $x$ & $x$ & $\mathrm{~A}$ \\
\hline 13 & 91 & 17 & $\mathrm{~L}$ & M & $\begin{array}{c}\text { Macular } \\
\text { Degeneration }\end{array}$ & 0.3 & 5 & $\checkmark$ & $\times$ & A \\
\hline 14 & 90 & 20 & $\mathrm{R}$ & M & $\begin{array}{c}\text { Macular } \\
\text { Degeneration }\end{array}$ & 0.3 & 2 & $\checkmark$ & $\checkmark$ & A \\
\hline 15 & 93 & 14 & $\mathrm{R}$ & M & $\begin{array}{c}\text { Macular } \\
\text { Degeneration }\end{array}$ & $\mathrm{U}$ & 6 & $x$ & $x$ & A \\
\hline 16 & 31 & 18 & $\mathrm{R}$ & $\mathrm{F}$ & Achromatopsia & 1.0 & 3 & $\checkmark$ & $\checkmark$ & $\mathrm{C}$ \\
\hline 17 & 78 & 18 & $\mathrm{R}$ & M & $\begin{array}{c}\text { Macular } \\
\text { Degeneration } \\
\text { Glaucoma }\end{array}$ & $\mathrm{U}$ & 2 & $x$ & $x$ & A \\
\hline 18 & 72 & 16 & $\mathrm{R}$ & $\mathrm{M}$ & Epiretinal Membrane & $\mathrm{U}$ & 7 & $\checkmark$ & $\checkmark$ & $\mathrm{A}$ \\
\hline 19 & 66 & 18 & $\mathrm{~L}$ & $\mathrm{~F}$ & Achromatopsia & 1 & 1 & $\checkmark$ & $\checkmark$ & $\mathrm{C}$ \\
\hline 20 & 71 & 17 & $\mathrm{R}$ & $\mathrm{F}$ & $\begin{array}{c}\text { Macular } \\
\text { Degeneration } \\
\text { Retinoschisis } \\
\text { S Cone Syndrome }\end{array}$ & 1 & 2 & $\checkmark$ & $\checkmark$ & A \\
\hline 21 & 34 & 16 & $\mathrm{R}$ & $\mathrm{M}$ & Ocular Albinism & 1 & 2 & $\checkmark$ & $\checkmark$ & $\mathrm{C}$ \\
\hline 22 & 75 & 22 & $\mathrm{R}$ & M & $\begin{array}{c}\text { Macular } \\
\text { Degeneration }\end{array}$ & 0.5 & 4 & $\checkmark$ & $x$ & A \\
\hline 23 & 58 & 20 & $\mathrm{R}$ & $\mathrm{F}$ & $\begin{array}{c}\text { Myopic } \\
\text { Degeneration, } \\
\text { Choroidal } \\
\text { Neovascularization }\end{array}$ & 1.2 & 2 & $x$ & $x$ & A \\
\hline 24 & 33 & 18 & $\mathrm{~A}$ & $\mathrm{~F}$ & Rod Cone Dystrophy & 2.1 & 3 & $\checkmark$ & $\checkmark$ & $\mathrm{C}$ \\
\hline 25 & 43 & 12 & $\mathrm{R}$ & $\mathrm{F}$ & Pseudotumor Cerebri & 1 & 1 & $x$ & $\checkmark$ & $\mathrm{A}$ \\
\hline 26 & 28 & 18 & $\mathrm{R}$ & $\mathrm{F}$ & $\begin{array}{c}\text { Retinopathy of } \\
\text { Prematurity }\end{array}$ & 1.4 & 1 & $x$ & $\checkmark$ & $\mathrm{C}$ \\
\hline 27 & 22 & 16 & $\mathrm{R}$ & $\mathrm{M}$ & Retinitis Pigmentosa & $\mathrm{U}$ & 2 & $x$ & $x$ & $\mathrm{~A}$ \\
\hline 28 & 49 & 17 & $\mathrm{R}$ & $\mathrm{F}$ & Optic Nerve Atrophy & 1.2 & 1 & $\checkmark$ & $\checkmark$ & $\mathrm{A}$ \\
\hline 29 & 78 & 16 & $\mathrm{R}$ & $\mathrm{F}$ & $\begin{array}{c}\text { Macular } \\
\text { Degeneration }\end{array}$ & $\mathrm{U}$ & 5 & $\checkmark$ & $x$ & A \\
\hline 30 & 36 & 14 & $\mathrm{R}$ & $\mathrm{F}$ & $\begin{array}{l}\text { Retinopathy of } \\
\text { Prematurity }\end{array}$ & 0.5 & 3 & $x$ & $\checkmark$ & $\mathrm{C}$ \\
\hline 31 & 33 & 20 & $\mathrm{R}$ & $\mathrm{F}$ & Achromatopsia & 1.3 & 2 & $\checkmark$ & $\checkmark$ & $\mathrm{C}$ \\
\hline 32 & 30 & 20 & $\mathrm{R}$ & $\mathrm{M}$ & Achromatopsia & 1 & 2 & $\checkmark$ & $\checkmark$ & $\mathrm{C}$ \\
\hline 33 & 37 & 16 & $\mathrm{R}$ & $\mathrm{F}$ & Genetic & 0.6 & 2 & $\checkmark$ & $\checkmark$ & $\mathrm{C}$ \\
\hline 34 & 68 & 19 & $\mathrm{R}$ & $\mathrm{F}$ & Achromatopsia & $\mathrm{U}$ & 2 & $\checkmark$ & $x$ & $\mathrm{C}$ \\
\hline 35 & 69 & 14 & $\mathrm{R}$ & $\mathrm{M}$ & Keratitis & $\mathrm{U}$ & 1 & $\checkmark$ & $\checkmark$ & $\mathrm{A}$ \\
\hline 36 & 63 & 15 & $\mathrm{R}$ & $\mathrm{F}$ & $\begin{array}{c}\text { Cataracts } \\
\text { Glaucoma Suspect }\end{array}$ & $\mathrm{U}$ & 4 & $x$ & $\checkmark$ & A \\
\hline 37 & 19 & 13 & $\mathrm{R}$ & $\mathrm{M}$ & Septo-optic Dysplasia & 0.7 & 2 & $x$ & $x$ & $\mathrm{U}$ \\
\hline 38 & 59 & 25 & $\mathrm{R}$ & $\mathrm{F}$ & $\begin{array}{c}\text { Retinopathy of } \\
\text { Prematurity }\end{array}$ & 0.5 & 5 & $x$ & $\checkmark$ & $\mathrm{C}$ \\
\hline 39 & 76 & 21 & A & M & $\begin{array}{c}\text { Macular } \\
\text { Degeneration } \\
\text { Glaucoma }\end{array}$ & $\mathrm{U}$ & 5 & $x$ & $\checkmark$ & A \\
\hline 40 & 38 & 18 & $\mathrm{R}$ & $\mathrm{F}$ & Glaucoma & $\mathrm{U}$ & 1 & $x$ & $x$ & $\mathrm{~A}$ \\
\hline
\end{tabular}

Table S2: Experiment 2 participants with low vision. Data are presented in the same format as Table S1. 


\section{References}

Avraham, G., Ryan Morehead, J., Kim, H. E., \& Ivry, R. B. (2021). Reexposure to a sensorimotor perturbation produces opposite effects on explicit and implicit learning processes. PLoS Biology, 19(3), e3001147.

Bond, K. M., \& Taylor, J. A. (2015). Flexible explicit but rigid implicit learning in a visuomotor adaptation task. Journal of Neurophysiology, 113(10), 3836-3849.

Bowman, K. J. (1980). The clinical assessment of colour discrimination in senile macular degeneration. Acta Ophthalmologica, 58(3), 337-346.

Brudner, S. N., Kethidi, N., Graeupner, D., Ivry, R. B., \& Taylor, J. A. (2016). Delayed feedback during sensorimotor learning selectively disrupts adaptation but not strategy use. Journal of Neurophysiology, $115(3), 1499-1511$.

Burge, J., Ernst, M. O., \& Banks, M. S. (2008). The statistical determinants of adaptation rate in human reaching. Journal of Vision, 8(4), 20.1-19.

Cheong, Y., Ling, C., \& Shehab, R. (2021). An Empirical Comparison between the Effects of Normal and Low Vision on Kinematics of a Mouse-Mediated Pointing Movement. International Journal of HumanComputer Interaction, 1-11.

Endo, T., Kanda, H., Hirota, M., Morimoto, T., Nishida, K., \& Fujikado, T. (2016). False reaching movements in localization test and effect of auditory feedback in simulated ultra-low vision subjects and patients with retinitis pigmentosa. Graefes Arch Clin Exp Ophthalmol, 254(5), 947-956.

Haith, A. M., Huberdeau, D. M., \& Krakauer, J. W. (2015). The influence of movement preparation time on the expression of visuomotor learning and savings. The Journal of Neuroscience, 35(13), 5109-5117.

Hinder, M. R., Riek, S., Tresilian, J. R., de Rugy, A., \& Carson, R. G. (2010). Real-time error detection but not error correction drives automatic visuomotor adaptation. Experimental Brain Research, 201(2), 191207.

Hutter, S. A., \& Taylor, J. A. (2018). Relative sensitivity of explicit reaiming and implicit motor adaptation. Journal of Neurophysiology, 120(5), 2640-2648. 
Jacko, J. A., Barreto, A. B., Marmet, G. J., Chu, J. Y. M., Bautsch, H. S., Scott, I. U., \& Rosa, R. H. (2000, November 13). Low vision: the role of visual acuity in the efficiency of cursor movement. Proceedings of the Fourth International ACM Conference on Assistive Technologies, 1-8. Presented at the Arlington, Virginia, USA. New York, NY, USA: Association for Computing Machinery.

Joiner, W. M., \& Smith, M. A. (2008). Long-term retention explained by a model of short-term learning in the adaptive control of reaching. Journal of Neurophysiology, 100(5), 2948-2955.

Keisler, A., \& Shadmehr, R. (2010). A shared resource between declarative memory and motor memory. The Journal of Neuroscience, 30(44), 14817-14823.

Kim, H. E., Avraham, G., \& Ivry, R. B. (2020). The Psychology of Reaching: Action Selection, Movement Implementation, and Sensorimotor Learning. Annual Review of Psychology.

Kim, H. E., Morehead, R., Parvin, D. E., Moazzezi, R., \& Ivry, R. B. (2018). Invariant errors reveal limitations in motor correction rather than constraints on error sensitivity. Communications Biology, 1, 19.

Kitazawa, S., Kohno, T., \& Uka, T. (1995). Effects of delayed visual information on the rate and amount of prism adaptation in the human. The Journal of Neuroscience, 15(11), 7644-7652.

Körding, K. P., \& Wolpert, D. M. (2004). Bayesian integration in sensorimotor learning. Nature, 427(6971), $244-247$.

Kotecha, A., O’Leary, N., Melmoth, D., Grant, S., \& Crabb, D. P. (2009). The functional consequences of glaucoma for eye-hand coordination. Investigative Ophthalmology \& Visual Science, 50(1), 203-213.

Krakauer, J., Ghez, C., \& Ghilardi, M. F. (2005). Adaptation to visuomotor transformations: consolidation, interference, and forgetting. The Journal of Neuroscience, 25(2), 473-478.

Lakens, D. (2013). Calculating and reporting effect sizes to facilitate cumulative science: a practical primer for t-tests and ANOVAs. Frontiers in Psychology, 4, 863.

Legge, G. E., Parish, D. H., Luebker, A., \& Wurm, L. H. (1990). Psychophysics of reading. XI. Comparing color contrast and luminance contrast. Journal of the Optical Society of America, 7(10), 2002-2010.

Lenoble, Q., Corveleyn, X., Tran, T. H. C., Rouland, J.-F., \& Boucart, M. (2019). Can I reach it? A study in age-related macular degeneration and glaucoma patients. Visual Cognition, 27(9-10), 732-739. 
Lerner, G., Albert, S., Caffaro, P. A., Villalta, J. I., Jacobacci, F., Shadmehr, R., \& Della-Maggiore, V. (2020).

The Origins of Anterograde Interference in Visuomotor Adaptation. Cerebral Cortex.

Liu, Y., Jiang, W., Bi, Y., \& Wei, K. (2021). Sensorimotor knowledge from task-irrelevant feedback contributes to motor learning. Journal of Neurophysiology, 126(3), 723-735.

Marko, M. K., Haith, A. M., Harran, M. D., \& Shadmehr, R. (2012). Sensitivity to prediction error in reach adaptation. Journal of Neurophysiology, 108(6), 1752-1763.

Massof, R. W., \& Fletcher, D. C. (2001). Evaluation of the NEI visual functioning questionnaire as an interval measure of visual ability in low vision. Vision Research, 41(3), 397-413.

McDougle, S. D., Boggess, M. J., Crossley, M. J., Parvin, D., Ivry, R. B., \& Taylor, J. A. (2016). Credit assignment in movement-dependent reinforcement learning. Proceedings of the National Academy of Sciences of the United States of America, 113(24), 6797-6802.

McDougle, S. D., Bond, K. M., \& Taylor, J. A. (2015). Explicit and Implicit Processes Constitute the Fast and Slow Processes of Sensorimotor Learning. The Journal of Neuroscience, 35(26), 9568-9579.

Merabet, L. B., Connors, E. C., Halko, M. A., \& Sánchez, J. (2012). Teaching the blind to find their way by playing video games. PloS One, 7(9), e44958.

Morehead, R., \& de Xivry, J.-J. O. (2021). A Synthesis of the Many Errors and Learning Processes of Visuomotor Adaptation. BioRxiv.

Morehead, R., \& Smith, M. (2017). The magnitude of implicit sensorimotor adaptation is limited by continuous forgetting. Presented at the Advances in Motor Learning \& Motor Control. Retrieved from https://groups.seas.harvard.edu/motorlab/Reprints/MLMC2017_abstract_Morehead.pdf

Morehead, R., Taylor, J. A., Parvin, D. E., \& Ivry, R. B. (2017). Characteristics of Implicit Sensorimotor Adaptation Revealed by Task-irrelevant Clamped Feedback. Journal of Cognitive Neuroscience, 29(6), $1061-1074$.

Pardhan, S., Gonzalez-Alvarez, C., \& Subramanian, A. (2011). How does the presence and duration of central visual impairment affect reaching and grasping movements? Ophthalmic \& Physiological Optics, 31(3), 233-239. 
Pardhan, S., Gonzalez-Alvarez, C., \& Subramanian, A. (2012). Target contrast affects reaching and grasping in the visually impaired subjects. Optometry and Vision Science, 89(4), 426-434.

Patel, S., Park, H., Bonato, P., Chan, L., \& Rodgers, M. (2012). A review of wearable sensors and systems with application in rehabilitation. Journal of Neuroengineering and Rehabilitation, 9(1), 21.

Poh, E., Al-Fawakari, N., Tam, R., Taylor, J. A., \& McDougle, S. D. (2021). Generalization of motor learning in psychological space (p. 2021.02.09.430542). doi:10.1101/2021.02.09.430542

Samad, M., Chung, A. J., \& Shams, L. (2015). Perception of body ownership is driven by Bayesian sensory inference. PloS One, 10(2), e0117178.

Shadmehr, R., \& Ahmed, A. A. (2020). Vigor. The MIT Press.

Shadmehr, R., Smith, M. A., \& Krakauer, J. (2010). Error correction, sensory prediction, and adaptation in motor control. Annual Review of Neuroscience, 33, 89-108.

Shyr, M. C., \& Joshi, S. S. (2021, September). Validation of the Bayesian sensory uncertainty model of motor adaptation with a remote experimental paradigm. 2021 IEEE 2nd International Conference on HumanMachine Systems (ICHMS), 1-6.

Taylor, J. A., \& Ivry, R. B. (2011). Flexible cognitive strategies during motor learning. PLoS Computational Biology, 7(3), e1001096.

Taylor, J. A., Krakauer, J. W., \& Ivry, R. B. (2014). Explicit and implicit contributions to learning in a sensorimotor adaptation task. The Journal of Neuroscience, 34(8), 3023-3032.

Timmis, M. A., \& Pardhan, S. (2012). The effect of central visual impairment on manual prehension when tasked with transporting-to-place an object accurately to a new location. Investigative Ophthalmology \& Visual Science, 53(6), 2812-2822.

Tomkinson, C. R. (1974). Accurate assessment of visual acuity in low vision patients. Optometry and Vision, 51(5), 321-324.

Tsay, J. S., Avraham, G., Kim, H. E., Parvin, D. E., Wang, Z., \& Ivry, R. B. (2020). The Effect of Visual Uncertainty on Implicit Motor Adaptation. Journal of Neurophysiology. 
Tsay, J. S., Haith, A., Ivry, R. B., \& Kim, H. E. (2021). Distinct processing of sensory prediction error and task error during motor learning.

Tsay, J. S., Kim, H. E., Haith, A. M., \& Ivry, R. B. (2021). Proprioceptive Re-alignment drives Implicit Sensorimotor Adaptation. BioRxiv.

Tsay, J. S., Kim, H. E., Parvin, D. E., Stover, A. R., \& Ivry, R. B. (2021). Individual differences in proprioception predict the extent of implicit sensorimotor adaptation. Journal of Neurophysiology.

Tsay, J. S., Lee, A., Ivry, R. B., \& Avraham, G. (2021). Moving outside the lab: The viability of conducting sensorimotor learning studies online. Neurons, Behavior, Data Analysis, and Theory.

Tsay, J. S., Parvin, D. E., \& Ivry, R. B. (2020). Continuous reports of sensed hand position during sensorimotor adaptation. Journal of Neurophysiology, 124(4), 1122-1130.

Tsay, J. S., \& Winstein, C. J. (2020). Five Features to Look for in Early-Phase Clinical Intervention Studies. Neurorehabilitation and Neural Repair, 1545968320975439.

van Beers, R. J. (2012). How does our motor system determine its learning rate? PloS One, 7(11), e49373.

van Beers, R. J., Wolpert, D. M., \& Haggard, P. (2002). When feeling is more important than seeing in sensorimotor adaptation. Current Biology: CB, 12(10), 834-837.

van der Kooij, K., Brenner, E., van Beers, R. J., Schot, W. D., \& Smeets, J. B. J. (2013). Alignment to natural and imposed mismatches between the senses. Journal of Neurophysiology, 109(7), 1890-1899.

Verghese, P., Tyson, T. L., Ghahghaei, S., \& Fletcher, D. C. (2016). Depth Perception and Grasp in Central Field Loss. Investigative Ophthalmology \& Visual Science, 57(3), 1476-1487.

Wei, K., \& Körding, K. (2010). Uncertainty of feedback and state estimation determines the speed of motor adaptation. Frontiers in Computational Neuroscience, 4, 11. 